\title{
T)

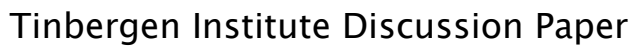 \\ Labor Market Prospects, Search Intensity and the Transition from College to Work
}

Bas van der Klaauw

Aico van Vuuren²

Peter Berkhout 3

${ }^{\prime}$ Faculty of Economics and Business Administration, Vrije Universiteit Amsterdam, CEPR, and Tinbergen Institute;

2 Department of Economics, Erasmus Universiteit Rotterdam;

${ }^{3}$ Foundation for Economic Research, Universiteit van Amsterdam. 


\section{Tinbergen Institute}

The Tinbergen Institute is the institute for economic research of the Erasmus Universiteit Rotterdam, Universiteit van Amsterdam, and Vrije Universiteit Amsterdam.

Tinbergen Institute Amsterdam

Roetersstraat 31

1018 WB Amsterdam

The Netherlands

Tel.: $\quad+31(0) 205513500$

Fax: $\quad+31(0) 205513555$

Tinbergen Institute Rotterdam

Burg. Oudlaan 50

3062 PA Rotterdam

The Netherlands

Tel.: $\quad+31(0) 104088900$

Fax: $\quad+31(0) 104089031$

Please send questions and/or remarks of nonscientific nature to driessen@tinbergen.nl.

Most TI discussion papers can be downloaded at http://www.tinbergen.nl. 


\title{
Labor Market Prospects, Search Intensity and the Transition from College to Work
}

\author{
Bas van der Klaauw* ${ }^{*}$ Aico van Vuuren ${ }^{\dagger}$ Peter Berkhout ${ }^{\ddagger}$
}

June 2004

\begin{abstract}
In this paper we develop a structural model for job search behavior of students entering the labor market. The model includes endogenous search effort and on-the-job search. Since students usually do not start a regular job before graduation but start job search earlier, our model is non stationary even if all structural parameters are constant. The model explains the common finding that a substantial share of individuals starts working immediately upon graduation. We estimate the model using a unique data set of individuals who completed undergraduate education in the Netherlands between 1995 and 2001. Our estimation results show that a 1 percent point decrease in unemployment rate increases wage offers with 3 percent, that there are substantial returns to work experience and that individuals devote less effort to job search than optimal. Employment rates at graduation could be increased from 40 percent to 65 percent if all individuals start job search 6 month prior to graduation.
\end{abstract}

*Free University Amsterdam, Tinbergen Institute, Scholar, and CEPR. Address: Department of Economics, Free University Amsterdam, De Boelelaan 1105, NL-1081 HV Amsterdam, The Netherlands. email: klaauw@tinbergen.nl

${ }^{\dagger}$ Erasmus University Rotterdam. Address: Department of Economics, Erasmus University Rotterdam, Burgermeester Oudlaan 50, NL-3062 PA Rotterdam, The Netherlands. email: vuuren@tinbergen.nl

${ }^{\ddagger}$ Foundation for Economic Research, University of Amsterdam. Address: Roetersstraat 29, NL-1018 WB Amsterdam, The Netherlands. email: peebee@seo.fee.uva.nl Keywords: business cycle, structural estimation, return to work experience. Acknowledgements: We thank Gregory Jolivet, Robert Shimer, Gerard van den Berg and participants at the 2004 CEPR-conference on the "dynamic approach to Europe's unemployment problem" in Bristol and seminars at IFAU-Uppsala, SOFI-Stockholm, RWI-Essen and IZABonn for useful comments. 


\section{Introduction}

Students anticipate the moment of graduation by searching for work already some period before graduating (e.g. Wolpin, 1987). Therefore, a substantial share of students starts working immediately after completing education (e.g. Bowlus, Kiefer and Neumann, 2001, Ferrall, 1997, and Wolpin, 1987). Young workers usually do not stay very long in their first job. Topel and Ward (1992) argue that young workers are searching for good matches, i.e. high paying jobs. Job-tojob transitions are often associated to wage increases and the behavior of young workers is largely consistent with job search theory. The high job turnover and fast wage growth can be the result of the existence of frictions within a stationary labor market environment faced by individuals. An alternative explanation for high job mobility and increasing wages is that the returns to work experience for new entrants in the labor market are relatively high. This implies that the labor market conditions faced by young workers change after they start working in their first job.

In this paper we develop a model describing labor market behavior of individuals around the moment of completing undergraduate education. Our model is a discrete-time job search model (see e.g. Mortensen, 1986, for an extensive discussion on models describing individual job search behavior). Unlike most empirical studies of individual labor market behavior, which take job search effort exogenously, we explicitly model the amount of job search effort (see Bloemen, 2004; Fougère, Pradel and Roger, 2002; Stern, 1989; and Yoon, 1981; for structural empirical analyses of job search models with endogenous search effort). Additionally, we model the optimal moment at which individuals start searching for work, which often precedes the date of graduation. The optimal timing of starting job search depends on the returns to job search and the costs of searching. We assume that the costs function of job search effort has two components, fixed costs made at the moment of starting job search, and flexible costs in each period depending on the amount of job search effort. Because students usually do not start working in regular jobs before actually graduating, the decision problem of students is non stationary (even if all structural elements of the model are constant over time). After the (optimal) moment of starting job search, students increase their job search effort and lower their reservation wage each period until the moment of graduating or accepting a job.

Our model explains the substantial share of individuals who start working immediately after graduation differently from the recent economic literature. Since we have information on the actual moment an individual starts searching for work, we can identify the job search process prior to graduation which can differ 
between individuals. Most closely related is Wolpin (1987), who imposes that all individuals start searching the same fixed period before graduation and that all individuals devote the same amount of effort to job search. Other structural empirical analyses do not explicitly model the job search process before graduation. Ferrall (1997) assumes that at the moment of leaving school all individuals have received exactly two job offers, and are employed if the wage associated to the best job offer exceeds the individual's reservation wage. Bowlus, Kiefer and Neumann (2001) ignore job search spells where an individual starts working immediately upon leaving school. Gras and Lindeboom (1994) adopt a similar strategy, but correct for potential selection among those who failed to find a job before graduation.

Young workers are mobile and wages tend to increase fast, which implies that the wage in the first job is not a proper indicator for the present value of life-time earnings (e.g. Eckstein and Wolpin, 1995). Therefore, we do not only model the job search process until accepting the first job, but we also allow for on-the-job search. Furthermore, we do not restrict the structural parameters describing the job search environment to be similar for individuals looking for their first job and for employed workers. This allows us to distinguish between the hypothesis that high job mobility and increasing wages are the result of frictions on the labor market as opposed to the hypothesis that this is the result of accumulating work experience.

Using a structural model has several advantages when modelling the labor market behavior of students. Within the structural model job search behavior, labor marker transitions and wages are jointly determined, and thus the interdependency between these variables can be studied. The structure of the model provides a way to handle individuals that have not been unemployed between leaving school and starting work. Since we allow for on-the-job search, our model provides estimates of the returns to early work experience. Finally, by explicitly modelling job search behavior, we obtain an estimate for the costs of job search.

In the empirical analyses we use data from an annual survey of young workers who recently finished undergraduate education at a Dutch university. In the Netherlands, it is unusual that after completing undergraduate education, people continue with Ph.D. education. Our data describes individuals who graduated in economics, business administration, Dutch law or psychology between 1995 and 2001. Since labor market conditions for these individuals differ, we estimate our model separately for different majors. Our data are unique in a sense that they are extensive on job search behavior, for example the data include the moment at which individuals actually start looking for work and the number of job applications. Furthermore, the data are rich on individual characteristics. It should 
be stressed that it is not our intention to estimate returns to education or to compare returns of the different studies. The latter would require an extended model, which includes the selection process into these studies.

The Dutch economy experienced a period of relatively fast economic growth at the end of the 1990s. This was characterized by improvements in labor market conditions, i.e. labor force participation rates, worker mobility, number of vacancies, and real wages increased. After 2000 the growth of the Dutch economy slowed down and the economy entered a period of recession. We investigate to what extent labor market prospects of students change as a result of macroeconomic changes. In particular, we allow the structural parameters to depend on business cycle indicators to investigate how labor market conditions affect the behavior of individuals. The effect of business cycle variation on individual search effort in our model is ambiguous, the direction depends on the values of the structural elements in the model (see also Shimer, 2004).

The estimation results allow us to compute how labor market prospects vary over the business cycle. Furthermore, we use the estimates to investigate the importance of the returns to early work experience and how these change over the business cycle. Wages increase not only due to real returns to work experience, but also labor market frictions cause increasing wage profiles. Therefore, studying wage accumulation over time does not provide a good measure for the returns to work experience. If there would not be any returns to work experience individuals change behavior, for example by setting a higher reservation wage for their first job. Our structural model allows to disentangle between the effect of labor market frictions on wages and early work experience, as well as it can deal with changes in individual behavior. Therefore, in this case the structural model provides ideal counterfactuals.

The outline of the paper is as follows. Section 2 provides some institutional background on the Dutch educational system and business cycle variation during the observation period. In Section 3 we present the structural model. The data are discussed in Section 4. In Section 5 we provide some details on the estimation of our structural model. Section 6 presents the estimation results of the structural model and analysis on the returns to early work experience. Section 7 concludes.

\section{Educational system in the Netherlands}

In this section we briefly discuss the university education system in the Netherlands. We mainly focus on elements that are relevant for the individuals studied in this paper. As mentioned in the introduction we only consider students, who 
finished undergraduate education with a major in economics, business administration, Dutch law or psychology.

All universities in the Netherlands are public and tuition fees for undergraduate students are low. The tuition fee is set by the government and does not vary by field of study or by university attended. Annual tuition fees for full-time students (under age 30) increased from around 800 euro in the early 1990s to around 1250 euro at the end of the 1990s. Undergraduate students are entitled to a uniform financial aid system. The grant depends on parental income and whether or not students live at their parents' house (see Leuven, Oosterbeek and Van der Klaauw, 2003, for a more extensive discussion). During the 1990s a number of changes occurred. First, a larger share of the grant was made dependent on parental income. In nominal terms the grant for students with low-earning parents remained between 300 euro and 350 euro monthly (dependent on living at the parents' house) during the 1990s, for students with high-earning parents nominal grants decreased more than 50 percent during the 1990s. Second, students with low-earning parents got access to a loan with a maximum of 150 euro in the early 1990s and over 400 euro at the end of the 1990s. Students typically use the grants, but are very reluctant to take up the loan. Third, the duration of entitlement to grants decreased. Students who started university education before 1990 received grants for a maximum of 6 years, from 1991 until 1995 the entitlement period was 5 years and in 1996 it was reduced to a maximum of 4 years. ${ }^{1}$

Undergraduate education is accessible for students who graduated from preuniversity track in secondary education and for students from higher vocational education. Universities are not permitted to select students, every student satisfying the entry requirements should be admitted. Traditionally most students entered university after pre-university track in secondary education. However, during the 1990s entry through higher vocational education became more popular. This is particularly true for economics and business administration where in 2002 around 45 percent of the students entered through higher vocational education compared to only 25 percent in 1992. For Dutch law and psychology these percentages are much lower.

Only a limited number of universities provide undergraduate studies with a major in economics, business administration, Dutch law or psychology. Currently 6 Dutch universities offer undergraduate programs in economics and business administration, 9 offer an undergraduate in law and 10 offer an undergraduate in

\footnotetext{
${ }^{1}$ During the 1990s the government also introduced a system where grants became loans if students did not pass a minimum number of courses in each year (see Leuven, Oosterbeek and Van der Klaauw, 2003). After its introduction this system has been modified a few times.
} 
psychology. At all universities the nominal duration of an undergraduate study in economics, business administration, Dutch law and psychology is 4 years (although most students do not actually graduate within this period). Students who enter university education through higher vocational education might get dispensation for classes, which they completed before. In the Netherlands a major is a specialization, students take almost 90 percent of their courses within their chosen major. $^{2}$ Therefore, undergraduate education is often the final stage of an individual's education. In the Netherlands annually around 200 Ph.D. students graduate in economics, business administration, law and psychology together, which is about 2.5 percent of the total number of graduates from undergraduate education in these fields. Even though undergraduate programs offered by different universities differ somewhat, they are considered to be close substitutes. They attract students from the same pool of potential students and they prepare students for the same labor market. Oosterbeek, Groot and Hartog (1992) compare the labor market outcomes of graduates from the different economics departments in the Netherlands and find that selection corrected wage differentials are modest.

Figure 1 presents total enrollment at Dutch universities during the period 1992 until 2002. From 1992 until 1998 the total number of students registered at a university decreased from around 187.500 to slightly over 160.000. After 1998 the number of students increased again to the level at the beginning of the 1990s. In Figure 2 we present first-year enrollment and the number of students finishing undergraduate education from 1992 to 2002. The number of graduates shows a peak in 1995/1996, probably due to the fact that the 1990/1991 cohort of students received grants for 6 years and the 1991/1992 cohort for 5 years. The pattern in first-year enrollment follows that of total enrollment closely. At the beginning of the 1990s the size of the relevant birth cohort decreased. In 1992 around 14 percent of the individuals between 18 and 23 years old were enrolled in a university. In 1997 this was 15 percent and it increased further to 17 percent in 2002. The latter can be explained from the increased popularity among graduates from higher vocational education to continue with university education.

Trends in graduation, first-year and total enrollment in economics, business administration, Dutch law and psychology follow the general trends closely. The

\footnotetext{
${ }^{2}$ Usually, students finish their undergraduate study with writing a short thesis (and maybe completing some final courses). Students can graduate each month, but most students graduate in August (slightly over 40 percent in our sample). There are some financial incentives not to postpone graduation, if a student graduates before the end of the academic year the students does not have to pay part of the tuition fee and after graduation an individual is entitled to receiving welfare benefits which are higher than the government grants.
} 
only exception is that for economics the increase in (first-year) enrollment at the end of the 1990s is somewhat larger than the general trend. Again this is caused by the fact that economics is particularly popular among graduates from higher vocational school.

During the end of the 1990s the Dutch economy experienced a period of relatively large economic growth. Figure 3 provides the change in GDP during our observation period and Figure 4 shows the unemployment rate. The year 2000 can be considered as the top of the business cycle. From 1994 until 2000 the growth rate of GDP was increasing and the unemployment rate was decreasing. After 2000 growth in GDP started to decline and at the end of 2001 the unemployment rate started to increase.

\section{The model}

In this section we present the model that we use to describe the transition from college to work. The model is a discrete-time job search model with endogenous search effort and on-the-job search. Burdett (1978) first derived a job search model that allowed for on-the-job search and Mortensen (1977) explicitly modelled search effort as an individual decision variable. Even though for an individual the structural parameters are constant over time, the model will be non stationary. This is caused by the fact that individuals can start searching for work before they graduate, but they (usually) do not start working in a regular job before the actual date of graduation. The model imposes that individuals choose their level of job search effort and reservation wage path to optimize their present value of future earnings. First, we consider the job search process before graduation. Next, we discuss the job search process after the moment of graduating including on-the-job search performed by employed workers.

\subsection{The search process before graduation}

Consider a student $\tau$ periods before graduation. The student can be in two possible states, actively searching for work or not searching for work. A student who is searching for work has to decide at the beginning of each period $\tau$ how much effort $s_{\tau} \geq 0$ to devote to job search. There are two types of costs associated to job search effort. First, fixed costs $c_{0}$ made only once at the moment the student starts searching for work actively. ${ }^{3}$ These fixed costs include for example writing a vitae and a draft of an application letter, registering at public employment offices

\footnotetext{
${ }^{3}$ Yoon (1981) assumes that a job searcher make some fixed costs in every period.
} 
and private matching agencies, etc. Second, there are some variable costs, denoted by $c_{u}\left(s_{\tau}\right)$, depending on the amount of job search effort, which involve checking newspapers for job advertisements, sending out applications, etc. A student who is not searching does not have these variable costs, i.e. $c_{u}(0)=0$. The costs of devoting job search effort are increasing in the amount of effort, $c_{u}^{\prime}\left(s_{\tau}\right)>0$, and we assume $c_{u}^{\prime \prime}\left(s_{\tau}\right)>0$ (Mortensen, 1986; and Stern, 1989; make similar assumptions to guarantee the existence of a reservation wage).

A student who devotes $\tau$ periods before graduation effort $s_{\tau}$ to job search, receives a job offer in this period with probability $0 \leq \lambda_{u}\left(s_{\tau}\right) \leq 1$. Students who do not devote any effort to job search cannot receive job offers, i.e. $\lambda_{u}(0)=0$. Increasing the amount of job search effort increases the probability of receiving a job offer, $\lambda_{u}^{\prime}\left(s_{\tau}\right)>0$, but the returns to job search effort diminish $\lambda_{u}^{\prime \prime}\left(s_{\tau}\right)<$ 0 . A job offer is characterized by its wage $w$, which is a realization from the (continuous) wage offer distribution function $F_{u}(w)$ (with finite mean, $\mathrm{E}_{F_{u}}(w)<$ $\infty)$. At the moment a job is offered, the student has to decide immediately to accept the job or to reject it and continue searching. We exclude the possibility to reconsider job offers at a later stage. Once the student decides to accept a job offer, he starts working in the new job immediately after graduating. We do not consider the possibility that a student already starts working before graduation. Neither do we allow for the possibility of continuing searching for a better job after a job has been accepted. This assumption simplifies the analysis. The main motivation for imposing the assumption is that a student, who already accepted a job and continues searching for work, is less credible for other employers.

Individuals have an infinite horizon and they know the values of $\lambda_{u}(\cdot), c_{0}$, $c_{u}(\cdot)$, and the distribution function $F_{u}(\cdot)$. However, they do not know in advance when job offers arrive and what the associated wages are. We assume that students maximize their expected present value of future income. Future income is discounted at the subjective rate $\rho>0$. For a student who is actually searching for work $\tau$ periods before graduation, we define $R_{u, \tau}$ as the present value of search. The Bellman's equation for the student satisfies

$$
\begin{aligned}
R_{u, \tau}= & \max _{s_{t} ; t=0, \ldots, \tau}\left\{-\frac{c_{u}\left(s_{\tau}\right)}{1+\rho}+\frac{\lambda_{u}\left(s_{\tau}\right)}{1+\rho} \mathrm{E}_{F_{u}}\left[\max \left\{\frac{R_{e}(W)}{(1+\rho)^{\tau-1}}, R_{u, \tau-1}\right\}\right]\right. \\
& \left.+\frac{1-\lambda_{u}\left(s_{\tau}\right)}{1+\rho} R_{u, \tau-1}\right\}
\end{aligned}
$$

where the wage $W$ is a random variable that follows the distribution $F_{u}(\cdot)$ and $R_{e}(w)$ is the value of working (after graduation) in a job with wage $w$. We de- 
rive $R_{e}(w)$ in the next subsection. For convenience we assume that the costs of job search effort $c\left(s_{\tau}\right)$ are made at the end of each period. From the Bellman's equation it can be seen that if the student receives a job offer with associated wage $w$ in period $\tau$, he accepts this job offer if the present value of accepting the job $R_{e}(w) /(1+\rho)^{\tau-1}$ exceeds the value of search $R_{u, \tau-1}$. As will be shown later $R_{e}(w)$ is an increasing function in $w$. Therefore, there exists some $\phi_{\tau}$ for which all job offers with wage $w$ larger than $\phi_{\tau}$ are acceptable to the student and job offers with a wage $w$ less than $\phi_{\tau}$ are rejected. So $\phi_{\tau}$ is the reservation wage of a student $\tau$ periods before graduation, which is found by solving

$$
\frac{R_{e}\left(\phi_{\tau}\right)}{(1+\rho)^{\tau-1}}=R_{u, \tau-1}
$$

Substituting this reservation wage property into the Bellman's equation gives the condition for the optimal reservation wage path

$$
\begin{aligned}
R_{e}\left(\phi_{\tau+1}\right)= & \max _{s_{t} ; t=0, \ldots, \tau}\left\{-c_{u}\left(s_{\tau}\right)(1+\rho)^{\tau-1}+\lambda_{u}\left(s_{\tau}\right) \mathrm{E}_{F_{u}}\left[\max \left\{R_{e}(W)-R_{e}\left(\phi_{\tau}\right), 0\right\}\right]\right. \\
& \left.+R_{e}\left(\phi_{\tau}\right)\right\}
\end{aligned}
$$

Result $1 \phi_{\tau} \geq \phi_{\tau-k}$ for all $\tau=1, \ldots$ and $k=1, \ldots, \tau$. Before graduation the reservation wage of a student $\phi_{\tau}$ is non increasing as the moment of graduation approaches.

\section{Proof in Appendix A.}

Next we determine the optimal amount of effort students devote to job search in each period. Given the reservation wage $\phi_{\tau}$, the optimal search effort $\tau$ periods before graduation is the search effort $s_{\tau}$ that maximizes $\phi_{\tau+1}$. The first-order condition for the optimal amount of job search effort is

$$
\frac{c_{u}^{\prime}\left(s_{\tau}\right)}{\lambda_{u}^{\prime}\left(s_{\tau}\right)}=\frac{1}{(1+\rho)^{\tau-1}} \int_{\phi_{\tau}}^{\infty}\left[R_{e}(x)-R_{e}\left(\phi_{\tau}\right)\right] d F_{u}(x)
$$

The left-hand side of the first-order condition is positive, and it is increasing in $s_{\tau}$ (recall that $c_{u}^{\prime \prime}\left(s_{\tau}\right)>0$ and $\left.\lambda_{u}^{\prime \prime}\left(s_{\tau}\right)<0\right)$. A necessary condition for a student to devote a positive amount of effort to job search $\tau$ periods before graduation is thus that the reservation wage $\phi_{\tau}$ should be such that

$$
\frac{c_{u}^{\prime}(0)}{\lambda_{u}^{\prime}(0)}<\frac{1}{(1+\rho)^{\tau-1}} \int_{\phi_{\tau}}^{\infty}\left[R_{e}(x)-R_{e}\left(\phi_{\tau}\right)\right] d F_{u}(x)
$$


The right-hand side is positive and decreasing in $\phi_{\tau}$, while the left-hand side is constant and positive. Let $\bar{\phi}_{\tau}$ be the maximum value for which the inequality still holds, which is decreasing in $\tau$. Recall from Result 1 that the reservation wage is non decreasing in $\tau$. If in some period $\tau$ the reservation wage exceeds $\bar{\phi}_{\tau}$ the student does not devote any effort to job search in this period, nor has the student devoted any effort to job search in the preceding periods.

Result 2 If $s_{\tau}>0$, then $s_{\tau}<s_{\tau-k}$ for all $\tau=1, \ldots$ and $k=1, \ldots, \tau$. Students, who have not accepted a job yet, increase their job search effort as the moment of graduation gets closer.

\section{Proof in Appendix A.}

So far we focused on students who were already actively searching for work. As mentioned above individuals have to make fixed costs $c_{0}$ to start searching for work. Consider a student who is not searching for work $\tau$ periods before graduation. This individual decides to start searching for work in this period if

$$
R_{u, \tau}-c_{0} \geq \max _{t=0, \ldots, \tau-1}\left\{\frac{R_{u, t}-c_{0}}{(1+\rho)^{\tau-t}}\right\}
$$

If we substitute $R_{u, \tau}=R_{e}\left(\phi_{\tau+1}\right) /(1+\rho)^{\tau}$, this condition becomes

$$
R_{e}\left(\phi_{\tau+1}\right)-c_{0}(1+\rho)^{\tau} \geq \max _{t=0, \ldots, \tau-1}\left\{R_{e}\left(\phi_{t+1}\right)-c_{0}(1+\rho)^{t}\right\}
$$

Using this inequality we can find the optimal moment $\tau_{0}$ for a student to start searching for work actively. This moment $\tau_{0}$ satisfies

$$
\tau_{0}=\arg \max _{\tau=1, \ldots}\left\{R_{e}\left(\phi_{\tau}\right)-c_{0}(1+\rho)^{\tau-1}\right\}
$$

The function $c_{0}(1+\rho)^{\tau-1}$ is the present value at the moment of graduation of the fixed search costs. It is increasing in $\tau$, meaning that the earlier a student starts searching for work, the higher the present value of the fixed search costs. Also $R_{e}\left(\phi_{\tau}\right)$ is an increasing function in $\tau$, implying that also the payoffs of starting with job search earlier are higher.

Result $3 \tau_{0}$ is non decreasing if $c_{0}$ decreases, i.e. lower fixed costs of starting job search do not cause a student to start searching for work actively shorter before the moment of graduation. 


\section{Proof in Appendix A.}

A student does not start searching at all before graduation if the payoffs of job search do not exceed the present value of the fixed costs, i.e. in each period $\tau=1, \ldots, R_{e}\left(\phi_{\tau}\right)<c_{0}(1+\rho)^{\tau-1}$. Given that a student starts searching for work before graduation, the moment at which the student starts is uniquely determined by equation (4). The function $R_{e}\left(\phi_{\tau}\right)-c_{0}(1+\rho)^{\tau-1}$ has a single optimum.

Result 4 The moment $\tau_{0}$ at which a student starts searching for work is unique or non-existing.

\section{Proof in Appendix A.}

To summarize the behavior of students, prior to period $\tau_{0}$, the student does not devote any effort to job search and thus does not obtain any job offers. After that the student starts searching with a relatively low job search effort, but increases job search effort each period (until graduation or accepting work). Since the student does not obtain job offers before $\tau_{0}$, the reservation wage is not specified prior to $\tau_{0}$. At $\tau_{0}$ the reservation wage is relatively high. Towards the moment of graduation the reservation wage is at least non increasing, but typically decreasing.

For a student who has not accepted a job until the beginning of period $\tau$, the probability of accepting a job in period $\tau$ equals

$$
\theta_{\tau}= \begin{cases}\lambda_{u}\left(s_{\tau}\right)\left(1-F_{u}\left(\phi_{\tau}\right)\right) & \text { if } \tau \leq \tau_{0} \\ 0 & \text { if } \tau>\tau_{0}\end{cases}
$$

Before $\tau_{0}$ students do not receive job offers and thus the probability of accepting work equals 0 . After $\tau_{0}$, the probability of accepting a job increases as the moment of graduation approaches.

Result $5 \theta_{\tau}<\theta_{\tau-k}$ for all $\tau=1, \ldots, \tau_{0}$ and $k=1, \ldots, \tau$.

\section{Proof in Appendix A.}

\subsection{The search process after graduation}

Upon graduation an individual can either become unemployed or can start working. An individual starts working if the individual already accepted a job while 
being student. Individuals can search for a new job when being employed and make a job-to-job transition. We do not allow the possibility that employed workers get fired from a job or that they quit working. ${ }^{4}$ Although employment is an absorbing state, a job is not absorbing as there can be job-to-job transitions. Individuals who become unemployed at graduation, either actively searched for work while being student but did not succeed in finding work or did not start searching for work yet. After the moment of graduation we can distinguish three possible states, (1) the individual is unemployed and actively searching for work, (2) the individual is unemployed and not actively searching for work, and (3) the individual is employed.

Consider an individual who did not start working yet. This individual is entitled to collecting a particular type of welfare benefits, denoted by $b$. Welfare benefits for school leavers are reduced benefits compared to those collected by other welfare recipients, like job losers. The level of the benefits depends on the housing situation. For most school leavers the level of the monthly gross welfare benefits is about 435 euro. School leavers often qualify for substantial housing subsidies, therefore we set the net monthly benefits level $b$ equal to 450 euro. These welfare benefits are paid for an unlimited period of time. After graduation the structural parameters, $c_{u}(s), \lambda_{u}(s), F_{u}(w)$ and $\rho$ remain the same as before graduation. Since the model is stationary (after graduation) unemployed workers choose each period the same amount of job search effort $s$ and the same reservation wage $\phi$. Let $R_{u}$ be the value of search of an unemployed worker. The Bellman's equation for an unemployed individual equals

$$
R_{u}=\max _{s \geq 0}\left\{\frac{b-c_{u}(s)}{1+\rho}+\frac{\lambda_{u}(s)}{1+\rho} \mathrm{E}_{F_{u}}\left[\max \left\{R_{e}(W), R_{u}\right\}\right]+\frac{1-\lambda_{u}(s)}{1+\rho} R_{u}\right\}
$$

From this equation it can be seen that welfare benefits $b$ are paid at the end of each period. The Bellman's equation can be rewritten as

$$
\rho R_{u}=b+\max _{s \geq 0}\left\{-c_{u}(s)+\lambda_{u}(s) \mathrm{E}_{F_{u}}\left[\max \left\{R_{e}(W)-R_{u}, 0\right\}\right]\right\}
$$

If an unemployed worker receives a job offer with wage $w$, he accepts the offer if $R_{e}(w) \geq R_{u}$. The reservation wage $\phi$ of the unemployed worker can be found by solving

$$
R_{e}(\phi)=R_{u}
$$

\footnotetext{
${ }^{4}$ In our data set we hardly observe transitions from being employed to unemployment. Of the individuals who were observed to have had at least 1 job, $99 \%$ is employed at the end of our observation period.
} 
For a given value of $\phi$, the optimal amount of job search effort $s$ follows the first-order condition

$$
\frac{c_{u}^{\prime}(s)}{\lambda_{u}^{\prime}(s)}=\int_{\phi}^{\infty}\left(R_{e}(w)-R_{e}(\phi)\right) d F_{u}(w)
$$

The left-hand side of the first-order condition is positive, and it is increasing in $s$. Therefore, a necessary condition for individuals to devote a positive amount of effort to job search is that the reservation wage $\phi$ should be such that

$$
\frac{c_{u}^{\prime}(0)}{\lambda_{u}^{\prime}(0)}<\int_{\phi}^{\infty}\left(R_{e}(w)-R_{e}(\phi)\right) d F_{u}(w)
$$

As the right-hand side is positive and decreasing in $\phi$, there exists some reservation wage $\bar{\phi}$ for which an unemployed worker does not devote any effort to job search.

The framework we discussed so far is stationary, which means that as long as an individual is unemployed, the individual has the same reservation wage and devotes in every period the same amount of effort to job search. It also implies that an individual who does not start searching for work immediately after graduating will never devote any effort to job search and will never start working. This latter contradicts our data as around 20 percent of the individuals has not yet performed any job search activities 1 month after graduation. Almost 10 percent of the individuals has not even started searching for work within 3 months after graduation. These individuals derive for some period an instantaneous utility from being unemployed which is much higher than the welfare benefits level, for example because they planned a long holiday after graduation instead of going to the labor market directly. For individuals who started only some months after graduation, we assume that for a fixed period with length $t_{0}$ immediately after graduation their instantaneous utility of being unemployed equals $\bar{b}$. The high value of $\bar{b}$ causes that $\phi>\bar{\phi}$. The individual does not devote any effort to job search $t_{0}-1$ periods after graduation. For the same reason this individual also does not search for work before graduation. In theory $\bar{b}$ could be infinite, implying that the individual definitely wants to be unemployed for $t_{0}$ periods after graduation and therefore would not want to run the risk of finding a job prior to the end of this period. We assume that $t_{0}$ and $\bar{b}$ are known to the individual already before graduation. Like students, who start searching for work, these individuals have to make fixed search $\operatorname{costs} c_{0}$ at the moment they first start searching for work $\left(t_{0}-1\right.$ periods after graduation).

Next, consider an employed individual receiving in each period wage $w$. While being employed, workers can search for other jobs, but they cannot lose their job. 
The search process of employed workers is similar to that of students and unemployed workers, but they face different structural parameters. The probability of receiving a job offer equals $\lambda_{e}(s)$ and wage offers are drawn from the wage offer distribution $F_{e}(w)$, which have the same properties as $\lambda_{u}(s)$ and $F_{u}(w)$ respectively. For employed workers there are only the variable costs $c_{e}(s)$ of devoting effort to job search, also $c_{e}(s)$ has the same properties as $c_{u}(s)$. As mentioned earlier $R_{e}(w)$ is the value of work with wage $w$, which comes from the Bellman's equation

$R_{e}(w)=\max _{s \geq 0}\left\{\frac{w-c_{e}(s)}{1+\rho}+\frac{\lambda_{e}(s)}{1+\rho} \mathrm{E}_{F_{e}}\left[\max \left\{R_{e}(W), R_{e}(w)\right\}\right]+\frac{1-\lambda_{e}(s)}{1+\rho} R_{e}(w)\right\}$

The Bellman's equation implies that wages are received at the end of a period. The equation can be rewritten as

$$
\rho R_{e}(w)=w+\max _{s \geq 0}\left\{-c_{e}(s)+\lambda_{e}(s) \mathrm{E}_{F_{e}}\left[\max \left\{R_{e}(W)-R_{e}(w), 0\right\}\right]\right\}
$$

From the Bellman's equation follows that $R_{e}(x)>R_{e}(y)$ if $x>y$, the value of work increases with the wage received by a worker. Therefore, employed workers accept a job offer if the associated wage exceeds their current wage $w$. The optimal amount of effort devoted to job search follows from the first-order condition

$$
\frac{c_{e}^{\prime}(s)}{\lambda_{e}^{\prime}(s)}=\int_{w}^{\infty}\left(R_{e}(x)-R_{e}(w)\right) d F_{e}(x)
$$

Since the right-hand side is a decreasing function in $w$ and the left-hand side is an increasing function in $s$, the optimal amount of job search effort $s$ is lower if individuals receive higher wages $w$. Individuals only devote a positive amount of effort to job search if

$$
\frac{c_{e}^{\prime}(0)}{\lambda_{e}^{\prime}(0)}<\int_{w}^{\infty}\left(R_{e}(x)-R_{e}(w)\right) d F_{e}(x)
$$

Since the left-hand side is positive and the right-hand side is decreasing in $w$, there is some wage $\bar{w}$ above which employed workers do not search for work anymore.

Result 6 There exists a wage level $\bar{w}$, for which $s=0$ if $w \geq \bar{w}$. For $w<\bar{w}, s$ is positive and decreasing in $w$. A worker reduces his job search effort if he receives 
a higher wage. If the wage exceeds a certain level, the worker does not devote any effort to job search (see also Mortensen, 1986). ${ }^{5}$

\section{Proof in Appendix A.}

This result implies that above the wage level $\bar{w}$, the value of working $R_{e}(w)$ equals $w / \rho$. An individual who reaches a wage level above $\bar{w}$, quits searching for work and stays in this job forever.

\subsection{Some remarks on the identification and parameteri- zation}

The unknown structural parameters of the model are the wage offer distributions $F_{u}(w)$ and $F_{e}(w)$, the job offer arrival probabilities $\lambda_{u}(s)$ and $\lambda_{e}(s)$, the variable costs function of job search $c_{u}(s)$ and $c_{e}(s)$, the initial costs of starting job search $c_{0}$, and the discount rate $\rho$. Before providing the parameterization of these structural parameters we discuss their identification.

Let us for a moment assume that we observe the reservation wage path from the moment an individual starts searching for work. In case we observe the exact moment $t$ at which the individual accepts a wage offer we can identify the wage offer distribution above the reservation wage $F_{u}\left(w \mid w>\phi_{t}\right)$. It is well known from Flinn and Heckman (1982) that the tail of the wage offer distribution below the reservation wage cannot be identified without information on wages associated to rejected job offers. Therefore, we cannot identify the wage offer distribution below the lowest possible reservation wage, which is the reservation wage after graduation. A similar identification problem arises for the wage offer distribution of employed workers searching for a new job. An employed worker accepts a new job if the wage offer $w$ exceeds his current wage $w_{c}$, so we can identify $F_{e}(w \mid w>$ $w_{c}$ ). Again we cannot identify the wage offer distribution below the lowest possible wage at which an individual is working, which is the earlier mentioned lowest possible reservation wage. So we can only identify $F_{e}(w)$ on the same support as $F_{u}(w)$. As will be mentioned below, to establish identification we assume that the shape of the wage offer distribution is known up to an unknown set of parameters.

Before starting the first job, the probability of accepting a job equals $\lambda_{u}\left(s_{t}\right)(1-$ $\left.F_{u}\left(\phi_{t}\right)\right)$. This hazard can be identified from the moment individuals start working. Without observing $s_{t}$, we can only identify the job offer arrival rate up to a

\footnotetext{
${ }^{5}$ Mortensen (1986) has a continuous-time framework and parameterizes the job offer arrival rate as $\lambda s$.
} 
normalization, as a high job offer arrival rate associated with a wage offer distribution that has some mass below the reservation wage cannot be distinguished from a low job offer arrival rate.

The costs function of job search effort is identified from observing job search effort, wages, and reservation wages. Recall that the function for the optimal amount of job search effort is given by equation (3) before graduation and equation (5) after graduation. These equations show that from observing job search effort $s$ we can identify the derivatives of the costs function of job search effort $c_{u}^{\prime}(s)$ and $c_{e}^{\prime}(s)$. Since $c_{u}(0)=c_{e}(0)=0$, we can actually identify for a given $s$ the costs function $c_{u}(s)$ as $\int_{0}^{s} c_{u}^{\prime}(x) d x$ and $c_{e}(s)$ as $\int_{0}^{s} c_{e}^{\prime}(x) d x$.

The discount rate $\rho$ is identified from the reservation wage path. In the differential equation (2) describing the optimal reservation wage path all elements except for $\rho$ are identified or observed. So solving the optimal reservation wage path identifies the discount rate $\rho$. However, estimation of $\rho$ turned out to be problematic even using simulated data. Therefore, we decided not to consider $\rho$ as a parameter to be estimated, but instead to fix its value to 0.20 annually. We estimated models with other values for the discount rate, but 0.20 gave the best fit.

The initial costs of job search $c_{0}$ are identified from the moment a student starts searching for work. Given that we do know all other structural parameters, the value of $c_{0}$ is given by equation (4), which ensures that $c_{0}$ is identified.

So far, we have supposed that the complete reservation wage path of the unemployed worker is observed. However, the data do not provide reservation wages. Flinn and Heckman (1982) stress that if reservation wages are unobserved, similar identification results can be derived. The identification hinges on the fact that the minimum of the accepted wages equals the reservation wage at graduation.

Next we provide the parameterization of the structural parameters. We allow the structural parameters to be dependent on individual characteristics. Let $x$ denote the vector of individual characteristics (including an intercept).

Both wage offer distributions follow a lognormal distribution function. The location parameter is $\mu$ for students and unemployed workers and $\psi_{\mu} \mu$ for employed workers. The scale parameters of the wage offer distribution is $\sigma^{2}$ for students and unemployed workers as well as for employed workers. The parameter $\psi_{\mu}$ can be interpreted as the returns to early work experience. Furthermore, we let $\mu$ depend on individual characteristics by $\mu=x \beta_{w}$.

The job offer arrival probability of unemployed workers and students follows a transformed logit specification

$$
\lambda_{u}(s)=\frac{\exp (\lambda s)-1}{\exp (\lambda s)} \quad s \geq 0
$$


Obviously, this is an exponential distribution with intensity $\lambda$

$$
\lambda_{u}(s)=1-\exp (-\lambda s) \quad s \geq 0
$$

This functional form ensures that the job offer probability equals 0 if an individual does not devote any effort to job search $(s=0)$. The probability of receiving a job offer increases in $s$, but the probability of receiving a job offer is restricted to be less than 1 . For employed workers we take the job offer probability equal to

$$
\lambda_{e}(s)=1-\exp \left(-\psi_{\lambda} \lambda s\right) \quad s \geq 0
$$

The parameter $\psi_{\lambda}$ can be considered as a measure for labor market efficiency of employed workers relative to unemployed workers and students. Finally, we allow $\lambda$ to be dependent on individual characteristics, i.e. $\lambda=\exp \left(x \beta_{\lambda}\right)$.

The costs functions of job search for unemployed workers and students and for employed workers follow

$$
c_{u}(s)=\exp (c s)-1 \quad c_{e}(s)=\exp \left(\psi_{c} c s\right)-1 \quad s \geq 0
$$

These costs functions equal 0 if an individual does not devote any effort to job search and are increasing in $s$. We assume that the parameter $c$ is similar for all individuals. We do not parameterize the initial costs of job search $c_{0}$ as this can easily be estimated nonparametrically. We return to the issue in Subsection 5.1.

\section{Data}

Our data are from a survey of individuals who completed undergraduate education in the Netherlands. ${ }^{6}$ The survey is a written questionnaire which contains questions on education, job search behavior, work history and personal characteristics. Each year in January or February individuals are interviewed who graduated in the academic year two years earlier. For example the sample collected in January 1999 contains individuals who graduated between September 1996 and August 1997. Individuals are interviewed only once and all information is retrospective. The data contain 7 waves, starting in 1997 until 2003. Yearly around 10,000 surveys are sent out and the response rate is between 40 and 45 percent.

From the waves we take all individuals who graduated in economics, business administration, Dutch law and psychology. Since our model describes individuals

\footnotetext{
${ }^{6}$ For each study a random sample of graduates is selected from the administration of the organization that coordinates enrollment of students at all Dutch universities and that makes the payments of grants to students.
} 
who first enter the labor market, we exclude individuals who did part-time education, were over age 30 at the moment of graduation, and who were full-time working before graduation. This results in a data set of 4505 individuals. Furthermore, we exclude 36 individuals, who are unemployed at the moment of the interview, never searched for work and report not to be interested in working, and 107 individuals whose answers are inconsistent, for example the moment of starting job search is later than the moment they started working or the second job started before the first job. Next we exclude 398 individuals with item nonresponse in the month of graduation or the moment of starting job search. Finally, we exclude 430 individuals who started working freelance, in a family company or their own company, became Ph.D. student or continued with another study. In total the reduced data set includes 3534 individuals. Table 1 provides the sample sizes stratified by study. Individuals within a particular major can be considered as relatively homogeneous, but there is definitely serious heterogeneity between the groups of students in different majors.

Let us first consider the individual's situation at the moment of the interview. An individual is considered to be employed if he has a job that contains at least 12 contractual working hours. For individuals with a major in economics, business administration or Dutch law employment rates at the moment of the interview are close to 1. For psychology graduates, employment rates at the moment of the interview display an increasing trend over the observation period, from around 0.85 in 1997 to over 0.95 in 2002 and 2003. Conditional on being employed, almost all individuals work full time, the average number of weekly contractual working hours is between 38 and 40 for economics, business administration and Dutch law graduates and about 34 for psychology graduates. For all groups there are no trends over calendar time.

Table 2 provides the real net monthly wages paid at the moment of the survey. These wages are measured in euro in February 1997 (the month of the first wave of the survey). Wages of psychology graduates are typically lower than wages for the other groups. The general picture is that there is an upward trend in real wages (for all groups of graduates) until 2002 and a (small) drop in 2003. This picture follows the general business cycle closely. Increasing wages can be caused by less frictions in the labor market, i.e. individuals receive more job offers. Therefore, we look at the percentage of individuals who switched jobs at least once before the interview. ${ }^{7}$ This job turnover rate is highest among psychology graduates, around 60 percent of the individuals had at least 2 jobs during the observation period and it shows a slightly increasing trend. For all groups about

${ }^{7}$ In the questionnaire it is explicitly mentioned that individuals should consider job changes within a firm as job-to-job transitions. 
40 to 45 percent of the individuals held more than 1 job. The data are not only informative on the wage in the job at the moment of the interview, but also on the wage in the first job after graduation. The real wage in this first job follows the same pattern as the current real wage.

The survey asks individuals in which month they graduated and in which month they started searching for work. There does not seem to be any trend in the number of months that students start job search prior to graduation. However, there are some differences between the groups of students. Around 75 percent of the economics and business administration graduates starts searching for work before graduation and almost 60 percent started at least 3 months before graduation. For Dutch law and psychology these percentages are lower, around 65 percent starts before graduation and slightly less than 50 percent started at least 3 months before graduation.

We see a similar picture for the fraction of students that works immediately upon graduation. There is no clear trend in this fraction within the different groups of graduates, but there are some differences between the groups of graduates. The ranking of the groups by the fraction of working immediately upon graduation largely coincides with the ranking by the fraction that starts job search early. In particular, around 43 percent of the economics and business administration graduates already has work at the moment of graduation, while approximately 33 percent of the Dutch law and psychology graduates start working immediately after graduating. Even though the fraction that works immediately upon graduation is relatively constant over the years, there is in the earlier surveys a downward trend in the fraction of individuals that is still unemployed 6 months after graduation.

The data contain information both about the number of job applications and about the number of job interviews. In the first two surveys individuals were asked about the total number of job applications and job interviews until the moment the first job was accepted. Since 1999 individuals have to report the total number of job applications and job interviews until the moment of the interview. In our empirical analyses we use the number of job applications as a measure for job search intensity. In Table 3 we present the average number of job applications per group of graduates. For all groups, except for psychology graduates, we see a downward trend in the number of job applications. In our empirical analyses we do not use the number of job interviews, but it is interesting to look at job interviews as these provides some insight in the tightness of the labor market. The number of job interviews is relatively constant over time, which implies that in the later years individuals needed less job applications to generate the same number of job interviews. Psychology students need on average the most job 
applications for obtaining one job interview.

The variables discussed above are the endogenous variables in our structural model. As mentioned in Subsection 3.3 we allow for observed heterogeneity in the job offer arrival rate and the wage offer distribution. Since we will estimate the model separately for each major, the samples are already relatively homogeneous. Due to business cycle variation individuals who graduated in different years faced different labor market conditions. To capture this business cycle variation we use GDP growth and the unemployment rate. We also include a dummy variable for being older than 25 years at the moment of graduation. If an individual is over 25 years old at the moment of graduation, this indicates that either the students entered university via the higher vocational school track or stayed in university for a long time. During our observation period there is a negative trend in the average age at graduation. This negative trend coincides with the shortening of the entitlement period of the government grants (see Section 2). There is no indication that students stayed in university shorter as a consequence of the improved labor market conditions in the later years of the observation period. We include dummy variables for medium grades and for high grades in university. In our sample approximately 53 percent has medium grades and 21 percent high grades. In psychology the percentage of graduates with high grades is slightly higher than in the other studies, but all percentages are constant over time. We also have information on high school grades, but these are not informative in addition to university grades.

About 53 percent of the individuals in our sample is man. There are large variations between majors. In economics 75 percent of the graduates is man, while in psychology this is only 17 percent. About 50 percent of the individuals has a father with either a degree from higher vocational school or a degree from university. This percentage is the same across studies and over time. And finally we include the region at which an individual lives. We distinguish between living in the west of the Netherlands or the rest of the Netherlands. The west area is the most urbanized area containing the four largest cities in Holland. In this area there are supposed to be more jobs available for university graduates and average wages are also higher. In our sample 65 percent of the individuals live in the west, while 55 percent of the individuals graduated from a university in the west.

\section{$5 \quad$ Estimation of the structural model}

In this section we discuss the estimation of the structural parameters $\lambda, \psi_{\lambda}, \mu$, $\psi_{\mu}, \sigma, c, \psi_{c}$ and $c_{0}$. 


\subsection{Preliminary issues}

The key problem of estimating the model is that at any point in time the present value of work $R_{e}(w)$ enters the decision problem of the individual (see Section 3). Because the model does not provide a closed-form solution for $R_{e}(w)$, we need to approximate $R_{e}(w)$.

Result 6 shows that there exists a wage level $\bar{w}$ above which employed workers do not search for work $\left(s_{e}(w)=0\right.$ for $\left.w \geq \bar{w}\right)$. This wage level follows from solving

$$
\frac{c_{e}^{\prime}(0)}{\lambda_{e}^{\prime}(0)}=\int_{\bar{w}}^{\infty}\left(R_{e}(x)-R_{e}(\bar{w})\right) d F_{e}(x)
$$

Because employed workers receiving wages $w$ above $\bar{w}$ stay in their job forever, their present value of work $R_{e}(w)$ equals $w / \rho$. Furthermore, we have parameterized $c_{e}^{\prime}(0)=\psi_{c} c$ and $\lambda_{e}^{\prime}(0)=\psi_{\lambda} \lambda$. Therefore, we can determine $\bar{w}$ by solving the condition

$$
\frac{\rho \psi_{c} c}{\psi_{\lambda} \lambda}=\int_{\bar{w}}^{\infty}(x-\bar{w}) d F_{e}(x)
$$

Since $F_{e}(w)$ is specified as a lognormal distribution function, the integral on the right-hand side can be solved analytically.

Given that an employed worker earns a wage $w$ less than $\bar{w}$, the condition for the optimal job search effort is given by equation (8). Solving this condition, given our parameterization provides the optimal amount of job search effort

$$
s_{e}(w)=\frac{1}{\psi_{c} c+\psi_{\lambda} \lambda}\left(\log \left(\frac{\psi_{\lambda} \lambda}{\psi_{c} c}\right)+\log \left(\int_{w}^{\infty}\left(R_{e}(x)-R_{e}(w)\right) d F_{e}(x)\right)\right)
$$

For employed workers who are actively searching for work, the present value of work $R_{e}(w)$ does not equal $w / \rho$, but instead is given by equation (7). If we substitute in this equation the condition for optimal job search effort and the parameterization, we get

$\rho R_{e}(w)=w-\left(\exp \left(\psi_{c} c s_{e}(w)\right)-1\right)+\left(1-\exp \left(-\psi_{\lambda} \lambda s_{e}(w)\right)\right) \frac{\psi_{c} c \exp \left(\psi_{c} c s_{e}(w)\right)}{\psi_{\lambda} \lambda \exp \left(-\psi_{\lambda} \lambda s_{e}(w)\right)}$

Note that $R_{e}(w)$ depends on $s_{e}(w)$, which depends on $R_{e}(x)$ for all $x \geq w$. Therefore, we cannot obtain analytical solutions for $s_{e}(w)$ and $R_{e}(w)$. We tried to approximate $R_{e}(w)$ by different types of polynomials, but we could not find any polynomial that had both an analytic solution for $\int_{w}^{\bar{w}}\left(R_{e}(x)-R_{e}(w)\right) d F_{e}(x)$ and a sufficiently good fit. ${ }^{8}$ Therefore, we choose a step-wise approximation for $R_{e}(w)$.

\footnotetext{
${ }^{8}$ Bloemen (2004) approximates $R_{e}(x)-R_{e}(w)$ by $(x-w) /(\rho+\sigma)$.
} 
Note that if $w \geq \bar{w}$, then $s_{e}(w)=0$ and $R_{e}(w)=w / \rho$. Since $F_{e}(w)$ follows a lognormal distribution function there is an analytic solution for $\int_{\bar{w}}^{\infty}(x-\bar{w}) d F_{e}(x)$. Next, taking the first-difference with respect to $w$ of both the left-hand side and the right-hand side of equation (7) shows

$$
\frac{\partial R_{e}(w)}{\partial w}=\frac{1}{\rho+\lambda_{e}\left(s_{e}(w)\right)\left(1-F_{e}(w)\right)}
$$

For a small $\Delta$ we can approximate

$$
R_{e}(w-\Delta) \approx R_{e}(w)-\Delta \frac{\partial R_{e}(w)}{\partial w}
$$

and

$$
\begin{aligned}
\int_{w-\Delta}^{\infty}\left(R_{e}(x)-R_{e}(w-\Delta)\right) d F_{e}(x) \approx & \int_{w}^{\infty}\left(R_{e}(x)-R_{e}(w)\right) d F_{e}(x) \\
& +\left(R_{e}(w)-R_{e}(w-\Delta)\right)\left(1-F_{e}(w)+\frac{\Delta}{2} f_{e}(w)\right)
\end{aligned}
$$

and $s_{e}(w-\Delta)$ follows from substituting the approximation for this integral in equation (9). So if we start from $R_{e}(\bar{w})=\bar{w} / \rho, s_{e}(\bar{w})=0$ and the analytic solution for $\int_{\bar{w}}^{\infty} R_{e}(x)-R_{e}(\bar{w}) d F_{e}(x)$, we can approximate $R_{e}(w)$ and $s_{e}(w)$ by the recursive formulas above. This approximation provides the behavior of the individual when being employed. Next, we should determine the reservation wage $\phi$ when being unemployed (after graduation) and the amount of search effort $s_{u}(\phi)$.

Since we know $R_{e}(w)$ we can compute for each $w$

$$
s_{u}(w)=\frac{1}{c+\lambda}\left(\log \left(\frac{\lambda}{c}\right)+\log \left(\int_{w}^{\infty}\left(R_{e}(x)-R_{e}(w)\right) d F_{u}(x)\right)\right)
$$

So we can find $\phi$ by solving

$$
\rho R_{e}(\phi)=b-c\left(s_{u}(\phi)\right)+\lambda_{u}\left(s_{u}(\phi)\right) \int_{\phi}^{\infty}\left(R_{e}(x)-R_{e}(\phi)\right) d F_{u}(x)
$$

The left-hand side is an increasing function in $\phi$ and the right-hand side is a decreasing function in $\phi$. The only numerical complication is that the integral on the right-hand side is taken with respect to $F_{u}(\cdot)$ instead of $F_{e}(\cdot)$. Finally, we can use equation (2) and equation (3) to determine the reservation wage path and the amount of job search effort each period before graduation.

We assume that wages are observed with measurement error. Let $\tilde{w}$ denote the observed wage and $w$ is the true wage. These are related according to $\log (\tilde{w})=$ 
$\log (w)+\varepsilon$, where $\varepsilon$ is normally distributed with mean 0 and variance $\sigma_{\varepsilon}^{2}$. The estimated variance of the measurement error can be interpreted as measure for the goodness of fit of the model. The model describes the data well when, compared to the sample variance in the observed logarithm of the wages, the variance in the measurement error $\sigma_{\varepsilon}^{2}$ is small.

Job search effort does not have a natural unit. Naturally, one interprets effort as the number of hours spent searching for work. Our data are not informative on the hours spent on job search, instead the data report the number of job applications. Like Bloemen (2004) we use the number of job applications as a measure for job search. Since making a job application does not always take the same number of hours, we assume that the number of job applications measures job search effort with an error. This measurement error has the same properties as the measurement error for observed wages, it is normally distributed with mean 0 and variance $\sigma_{s}^{2}$.

\subsection{Estimation}

Our estimation procedure proceeds in three steps using conditional maximum likelihood estimation. The main reason for adopting this three step procedure instead of estimating all parameters jointly is the speed of the estimation procedure. Joint estimation of all parameters implied a long time for each iteration and very slow convergence. In the first step of our estimation procedure, we condition on the optimal amount of job search effort and the optimal moment of starting job search. As in this step we only use data on job search spells, employment spells and wages, we can only estimate the parameters $\eta=\lambda / c, \psi_{\eta}=\psi_{\lambda} / \psi_{c}$, $\mu, \psi_{\mu}, \sigma$, and $\sigma_{\varepsilon}$. In the second step we use the observed amount of job search effort to estimate $\lambda, \psi_{\lambda}, c$ and $\psi_{c}$. And, in the third step we use the starting date of job search to estimate $c_{0}$. For the ease of presentation we suppress covariates. Because we observe individuals from the start of their career, we do not face initial conditions problems.

Step 1: estimation of $\eta, \psi_{\eta}, \mu, \psi_{\mu}, \sigma$, and $\sigma_{\varepsilon}$ In the ideal case, we observe for each individual the job search duration before graduation, the period of being unemployed, the wage in the first job, the length of the first job spell, the wage in the second job, etc. Unfortunately, we do not observe exact job spells, instead we observe the date at which an individual started working in the first job and in the current job, the first wage and current wage, and whether an individual has had one, two, or more jobs before the interview. So, the data are ideal for individuals who had at most two jobs until the interview. But, for individuals who had more 
than two jobs, we lack information. ${ }^{9}$ To keep the likelihood function trackable, we use for all individuals only information until accepting the second job. More precisely, if an individual had more than two jobs, we use the wage in the first job and the duration of the first job spell, i.e. the first job spell ended at least before the current job started.

Likelihood contributions are most complicated for individuals who had two jobs before the interview, other observations are special cases or involve only minor modifications. Therefore, we only discuss the likelihood contribution for an individual with two jobs. Let $\tau_{0}$ denote the period that a student starts searching for work previous to graduation and $t_{0}$ denote the duration of the search period until finding the first job, $t_{1}$ is the length of the first job spell. For ease of exposition assume that the first job has been accepted after graduation $\left(t_{0}>\tau_{0}\right) .{ }^{10} \mathrm{In}$ the first job the observed wage equals $\tilde{w}_{1}$ and in the second job $\tilde{w}_{2}$.

The likelihood contribution equals

$$
\begin{aligned}
\ell= & \left(\prod_{\tau=1}^{\tau_{0}}\left(1-\theta_{u, \tau}\right)\right)\left(1-\theta_{u, 0}\right)^{t_{0}-\tau_{0}-1} \theta_{u, 0} \int_{\phi}^{\bar{w}} \varphi\left(\frac{\log \left(\tilde{w}_{1}\right)-\log \left(w_{1}\right)}{\sigma_{\varepsilon}}\right) \frac{1}{\sigma_{\varepsilon} \tilde{w}_{1}} \\
& \left(1-\theta_{e}\left(w_{1}\right)\right)^{t_{1}-1} \theta_{e}\left(w_{1}\right) \int_{w_{1}}^{\infty} \varphi\left(\frac{\log \left(\tilde{w}_{2}\right)-\log \left(w_{2}\right)}{\sigma_{\varepsilon}}\right) \frac{1}{\sigma_{\varepsilon} \tilde{w}_{2}} \\
& \frac{\varphi\left(\frac{\log \left(w_{2}\right)-\psi_{\mu} \mu}{\sigma}\right) \frac{1}{\sigma w_{2}}}{1-\Phi\left(\frac{\log \left(w_{1}\right)-\psi_{\mu} \mu}{\sigma}\right)} d w_{2} \frac{\varphi\left(\frac{\log \left(w_{1}\right)-\mu}{\sigma}\right) \frac{1}{\sigma w_{1}}}{1-\Phi\left(\frac{\log (\phi)-\mu}{\sigma}\right)} d w_{1}
\end{aligned}
$$

As the true wages in the first and the second job are not observed, the likelihood contribution contains two integrals. The first integrates over all possible wages in the first job, with the reservation wage $\phi$ (at the moment of accepting the job) as lower bound and the maximum wage $\bar{w}$ at which the individual continues on-the-job search as upper bound. The second integral integrates over all possible true wages in the second job, the true wage in the second job should exceed the true wage in the first job. The second integral is the convolution of a lognormal distribution and a truncated lognormal distribution function, which has a relatively simple closed-form solution. The first integral does not have a closed-form solution and therefore numerical integration is required. The absence of an analytical solution is due to the distribution of the duration of the (first) job spell, $\left(1-\theta_{e}\left(w_{1}\right)\right)^{t_{1}-1} \theta_{e}\left(w_{1}\right)$.

\footnotetext{
${ }^{9}$ Around 12 percent of the individuals had more than two jobs before the interview. This percentage is highest among psychology graduates with almost 22 percent.

${ }^{10}$ If the individual started working immediately upon graduation, we summarize over the possible time period in which the individual could have accepted the job.
} 
It is important to stress that the parameters $\lambda$ and $c$ only enter the likelihood function as ratio of each other, i.e. if both $\lambda$ and $c$ are multiplied by some constant, then $\phi, \lambda_{u}\left(s_{u}(\phi)\right)$, and $\lambda_{e}\left(s_{e}(w)\right)$ are unaffected. The same holds for $\psi \lambda$ and $\psi_{c}$. This is well known in the literature and implies that based on data on unemployment spells, employment spells and wages only the parameters $\eta=\lambda / c$ and $\psi_{\eta}=\psi_{\lambda} / \psi_{c}$ can be identified.

Step 2: estimation of $\lambda, \psi_{\lambda}, c$, and $\psi_{c}$. In this step we use the observed number of job applications $\tilde{s}$ and the estimates from the first step to disentangle $\lambda$ and $c$, and $\psi_{\lambda}$ and $\psi_{c}{ }^{11}$ For ease of exposition we discuss the estimation procedure for an individual who had only one job during the observation period, and found this job after graduation. The likelihood contribution of this individual is given by

$$
\begin{aligned}
\ell\left(\tilde{s} \mid \tau_{0}, t_{0}, \tilde{w}_{1}, t_{1}\right)= & \frac{\int_{\phi}^{\infty} \ell\left(\tilde{s} \mid t_{1}, w_{1}, t_{2}\right) \ell\left(\tilde{w}_{1} \mid w_{1}\right) \ell\left(w_{1}\right) d w_{1}}{\int_{\phi}^{\infty} \ell\left(\tilde{w}_{1} \mid w_{1}\right) \ell\left(w_{1}\right) d w_{1}} \\
= & \frac{1}{\int_{\phi}^{\infty} \varphi\left(\frac{\log \left(\tilde{w}_{1}\right)-\log \left(w_{1}\right)}{\hat{\sigma}_{\varepsilon}}\right) \frac{1}{\hat{\sigma}_{\varepsilon} \tilde{w}_{1}} \varphi\left(\frac{\log \left(w_{1}\right)-\hat{\mu}}{\hat{\sigma}}\right) \frac{1}{\hat{\sigma} w_{1}} d w_{1}} \\
& \left(\int_{\phi}^{\infty} \varphi\left(\frac{\log (\tilde{s})-\log \left(\sum_{\tau=1}^{\tau_{0}} s_{u}\left(\phi_{\tau}\right)+\left(t_{0}-\tau_{0}\right) s_{u}(\phi)+t_{1} s_{e}\left(w_{1}\right)\right)}{\sigma_{s}}\right) \frac{1}{\sigma_{s} \tilde{s}}\right. \\
& \left.\varphi\left(\frac{\log \left(\tilde{w}_{1}\right)-\log \left(w_{1}\right)}{\hat{\sigma}_{\varepsilon}}\right) \frac{1}{\hat{\sigma}_{\varepsilon} \tilde{w}_{1}} \varphi\left(\frac{\log \left(w_{1}\right)-\hat{\mu}}{\hat{\sigma}}\right) \frac{1}{\hat{\sigma} w_{1}} d w_{1}\right)
\end{aligned}
$$

The amount of search effort before graduation $s_{u}\left(\phi_{\tau}\right)$, while being unemployed after graduation $s_{u}(\phi)$ and while being employed $s_{e}\left(w_{1}\right)$ are computed using the recursive formulas discussed in Subsection 5.1. The integral in the denominator of the first term has a closed-form solution, but the second integral does not have a closed-form solution as it depends on the true amount of search effort. Therefore, this term should be approximated numerically.

Similarly, we can derive the likelihood function of individuals, who never found work and individuals who had two jobs before the moment of the interview. Complications arise for individuals who had more than two jobs. For these individuals we do not observe the exact number of jobs and thus also not the length of each job spell. Therefore we ignore individuals who had more than two jobs. It should be noted that this does not cause any selectivity problems, as in the first step we have explicitly modeled the number of jobs of each individual.

\footnotetext{
${ }^{11}$ Recall from Section 4 that in the 1997 and 1998 surveys individuals were asked about the number of job applications until accepting the first job and in the later surveys individuals had to report all job applications until the moment of the interview.
} 
We optimize the loglikelihood function with respect to the parameters $\lambda, c$, $\psi_{\lambda}$ and $\psi_{c}$. The loglikelihood function depends on parameters that are estimated in the first step, therefore we need to adjust the standard errors for $\lambda, c, \psi_{\lambda}$ and $\psi_{c}$. To correct the standard errors we use Theorem 6.1 of Newey and McFadden (1994). We also estimate the covariance between the estimators in the second step and in the first step. This is a straightforward extension from Newey and McFadden (1994).

Step 3: estimation of $c_{0}$ In this third step we use the observed month of starting job search to estimate the fixed costs of starting job search $c_{0}$. Result 3 states that the optimal moment of starting job search is a monotone function of $c_{0}$, in particular $\tau_{0}$ cannot decrease if $c_{0}$ decreases. The optimal moment of starting job search is given by equation (4). Given $\tau_{0}$ we can bound $c_{0}$ by

$$
\frac{1}{\rho(1+\rho)^{\tau_{0}}}\left(R_{e}\left(\phi_{\tau_{0}+2}\right)-R_{e}\left(\phi_{\tau_{0}+1}\right)\right) \leq c_{0} \leq \frac{1}{\rho(1+\rho)^{\tau_{0}-1}}\left(R_{e}\left(\phi_{\tau_{0}+1}\right)-R_{e}\left(\phi_{\tau_{0}}\right)\right)
$$

For all individuals who started searching for work before graduation, we can compute both bounds for $c_{0}$. Recall from Section (3) that individuals who did not start searching for work before graduation receive utility from not working immediately after graduation. This implies that the behavior of these individuals is not informative about $c_{0}$. Therefore, we ignore these individuals in this step and estimate $c_{0}$ only using individuals who started searching for work before graduation. For each study we compute the density function for $c_{0}$ and we use kernel smoothing to obtain a relatively smooth density function for $c_{0}$.

\section{Results}

In this section we discuss the estimation results of the structural model. First, we provide the parameter estimates and discuss the fit of the model. Next, we focus on the returns to work experience.

\subsection{Parameter estimates}

Students in different majors differ from each other and these differences are most likely not fully captured by the observed individual characteristics included in the model. Therefore, we will not focus on the returns to the different majors. Individual characteristics are mainly used as control variables, without giving strong causal interpretations to covariate effects. Table 4 provides the parameter estimates of the structural model. 
The $\chi^{2}$-tests reported in Table 4 show that except for psychology graduates individual characteristics are important in explaining differences in job offer arrival rates $\lambda$ between individuals. For all groups individual characteristics are jointly significant in the mean log wage offer $\mu$. In many cases covariates have opposite effects on the job offer arrival rate and the wage offer distribution. For example individuals with low grades have higher job offer arrival probabilities (at a given search effort) than individuals with high grades, who receive on average higher wage offers. In most cases the impact on the wage offer distribution dominates in explaining labor market prospects, i.e. at the moment of graduation individuals with high grades have higher reservation wages than individuals with low grades. The opposite impact of covariates on the job offer arrival rate and the wage offer distribution can be explained from individual search behavior. Individuals with high grades might be looking for other types of jobs than individuals with low grades. Indeed individuals with high grades more often find a first job that requires university education. ${ }^{12}$ These jobs pay higher wages, but are more difficult to obtain. Furthermore, males and individuals whose father finished higher education receive better wage offers and have lower job offer arrival rates than their counterparts. For most groups labor market prospects are better in the west of the Netherlands, which is in agreement with the empirical results of Bloemen (2004).

Both the job offer arrival rate and the wage offer distribution can vary over calendar time. In particular, we allow these structural parameters to depend on the state of the business cycle at the moment of graduation. ${ }^{13}$ As indicators for the business cycle we use GDP growth and the unemployment rate (see Figures 3 and 4). Because almost all individuals find their job in the time interval from 6 months prior to graduation until 6 months after graduation, we smooth the values for GDP growth and the unemployment rate by taking their average values in this time period. The correlation between the smoothed series of GDP growth and the unemployment rate is -0.40 . For all groups the unemployment rate is a more important business cycle indicator than GDP growth. Mean wage offers are significantly lower in periods when the unemployment rate is high. The impact of the unemployment rate on the wage offer distribution does not differ much

\footnotetext{
${ }^{12}$ Our data contain some information on job characteristics, such as required level of education and sector.

${ }^{13}$ Ideally, one would like the business cycle to have an ongoing effect on the job offer arrival rate and the wage offer distribution. However, including such business cycle effects in the model requires making assumptions about individuals' predictions of the business cycle and to what extent they are aware of uncertainty concerning economic conditions. In such a model not only the current state of the business cycle is relevant, but also beliefs about future economic conditions directly enter the Bellman's equations described in Section 3.
} 
between groups, a 1 percent point increase in the unemployment rate lowers mean real wage offers with approximately 3 percent. Recall that between the mid-nineties and 2001 the unemployment rate dropped from around 7 percent to 2 percent, implying that real wage offers increased on average 15 percent. Only for Dutch law and psychology graduates the business cycle has a significant impact on the job offer arrival rate. A decrease in the unemployment rate increases the probability of receiving a job offer (at a fixed search effort) and for Dutch law graduates also an increase in GDP growth increases job offer arrival probabilities.

It is interesting to pay some attention to the question why the business cycle affects the job offer arrival rate of psychology graduates more than the job offer arrival rate of other groups. Recall from Section 4 that labor market outcomes of psychology student are not as good as of the other groups, in particular two years after graduation there is more unemployment among psychology graduates. This suggests that the labor market for psychology graduates is less tight than for the other groups. Finding work has not been the main problem for individuals who graduated in economics, business administration and Dutch law. Therefore, increased demand for skilled labor associated with the improved business cycle conditions at the end of the nineties caused that employers had to raise wages to attract employees. This is expressed in the increased fraction of individuals who graduates in economics, business administration and Dutch law that finds a first job which requires university education, i.e. this percentage increased from around 60 at the beginning of the observation period until almost 70 in later years. Psychology graduates had more difficulties finding work, so improvements in the business cycle could actually make it more easy for them to find better paying jobs. However, unlike for the other groups we do not see an increasing trend in the percentage of psychology graduates that find a first job which requires university education. This has been around 50 percent in all years of the observation period, but in the later years they indicate that the content of the job connects well to the study.

Shimer (2004) argues that individuals might lower their job search effort if labor market conditions improve. In our model, the search environment is mainly determined by the unemployment rate. In Figure 5 we show for all four groups the average optimal amount of search effort (at the moment of graduation conditional on being unemployed) as a function of the unemployment rate. Dutch law graduates is the group which makes most job applications per month, on average they write 2 application letters per month, while business administration graduates make only slightly more than 1 job application per month. Individuals devote less effort to job search in periods with high unemployment, although the optimal amount of job search effort does not seem to be very sensible to business cycle 
variation. This seems to contradict the theoretical predictions of Shimer (2004), even though our population consists of high educated workers who face favorable labor market conditions. However, Shimer (2004) considers a setting where the business cycle only directly affects the job offer arrival rate. If in our model the unemployment rate would only affect the job offer arrival rate, we would get as predicted by Shimer (2004) that higher unemployment increases search effort. We note that our estimated probabilities of receiving a job offer are much lower than the values Shimer (2004) requires for obtaining his predictions. ${ }^{14}$

In Figures 6 and 7 we show for each group the estimated reservation wage at the moment of graduation $(\phi)$ and the estimated lowest wage at which employed workers do not devote any effort to on-the-job search $(\bar{w})$. The reservation wage at the moment of graduation is a measure for the labor market prospects of students while the highest wage at which employed workers still search for work reflects the opportunities for employed workers to find better paying jobs. We find similar patterns for all groups, the reservation wages and the lowest wage at which individuals stop searching follow the business cycle closely. Reservation wages are highest for economics graduates and lowest for psychology graduates. Individuals who graduated in business administration continue searching up to a higher wage than the individuals in other groups. This is the result of the relatively high value of the variance in the wage offer distribution $\sigma^{2}$ for business administration graduates.

For graduates in business administration job search while being unemployed is most expensive. The variable costs of making one job application per month are for these individuals almost 60 euro, while for the other groups the variable costs are between 13 and 30 euro. Job search is much more expensive for employed workers than for unemployed workers, the estimates for $\psi_{c}$ are for all groups significantly larger than 1. This coincides with the finding of Bloemen (2004) and reflects that the value of leisure is higher for employed workers than for unemployed workers. However, job applications of employed workers are more likely to generate a job offer than job applications of unemployed workers, $\psi_{\lambda}$ is for all groups larger than 1 but only significantly for Dutch law and psychology graduates. These individuals enter another labor market after accepting their first job, i.e. more jobs become accessible. Bowlus, Kiefer and Neumann (2001) find

\footnotetext{
${ }^{14}$ On average the monthly probabilities of receiving a job offer (at the optimal job search effort at the moment of graduation) do not vary much over calendar time for individuals who graduated in economics, business administration and Dutch law, these probabilities are 0.44, 0.27 and 0.23 respectively. For psychology graduates there is an increasing trend during the observation period in the probability of receiving a job offer. In the beginning of the observation period this probability was 0.17 and it increased to 0.30 at the end of the observation period.
} 
that the probability of receiving a job offer is lower while being employed than while being unemployed. Our results show that job search is actually more efficient while being employed, but as search costs are higher employed workers devote less effort to job search than unemployed workers or students and therefore receive less job offers. For Dutch law and psychology graduates the wage offer distribution does not vary significantly between unemployed and employed individuals. For economics and business administration graduates there is a significant difference in the wage offer distribution between employed and unemployed individuals. Mean wage offers are higher while being employed, the difference is significant but quantitatively not large. In the next section we return to the differences in search environment between unemployed and employed individuals.

To get some insight in the performance of the model we report in Table 5 the observed and predicted number of jobs until the survey date and the employment rate at graduation. Both the predicted number of jobs and the employment rate at the moment of graduation are close to their observed values in the data, which indicates a good fit of the model. Also the estimated variance of the measurement errors is a measure of fit of the model. The variance in the logarithm of the observed real wages equals $0.0615,0.0585,0.0595$ and 0.1203 for economics, business administration, Dutch law and psychology graduates respectively. Comparing these to the estimated variances of the measurement errors $\sigma_{\varepsilon}^{2}$, indicates that our model explains 47 percent of the variance in the logarithm of wages for economics graduates, 65 percent for business administration graduates, 56 percent for Dutch law graduates and 49 percent for psychology graduates. Given that our populations are very homogenous these percentages are very high. This implies that the first step of our estimation procedure did well, the model provides a good fit of the wages and the unemployment and job durations.

In the second step of the estimation procedure we fit the number of job applications to the predicted search effort. The estimated variance of the measurement errors is large compared to the variance in the observed number of job applications. This indicates that the fit in the second step is poor. In particular, our model overestimates the number of job applications. An explanation that on average individuals apply less for work than predicted by our model is that many individuals do not continue searching for work once they start their first job. In the data 47 percent of the economics graduates did not continue searching onthe-job after accepting the first job, and these percentages are 42, 40 and 21 for business administration, Dutch law and psychology graduates respectively. Using the model we can estimate the fraction of individuals that should search on-thejob in the first job. Let $\phi$ be the reservation wage at the moment of accepting the first job and $\bar{w}$ is the wage at which individuals quit searching on-the-job, than 
the probability that an individual should continue searching after accepting the first job is $F_{u}(w \leq \bar{w} \mid w>\phi)$, which is the probability that an acceptable wage for the first job is less than $\bar{w}$. According to our model for all groups at any point in time more than 99 percent should search on-the-job in the first job.

There may be a number of reasons why individuals search less for work than optimal. After accepting a job individuals may wait some period before they start searching for a next job. There might be a negative stigma attached to quitting a job soon after starting. Also there may be some fixed costs associated to starting searching on-the-job. Or it might be the case that firms offer tenure profiles, i.e. individuals know that if they stay in a job their wage will increase gradually over time or that they will get promoted after some period. However, recall that if someone changed job within firms, this should be registered as different jobs. We performed a simple regression of whether individuals continued searching in the first job on the characteristics of the first job. This shows that for all groups the most important reasons not to continue searching are if university education is required for the job and if the job offers a permanent contract. Psychology graduates are also less likely to continue searching for work if the first job contains more contractual hours and if they work for the government.

Figure 8 presents the non-parametric densities of the startup costs for the different studies. In general, the estimated startup costs are very large for all groups. These high search startup costs imply that the model has difficulties explaining why individuals do not start searching for work early. Given that labor market conditions are very favorable for university graduates, reasonable startup costs imply that students should start searching for work much earlier than observed in the data. A possible explanation that students wait relatively long is that employers might be reluctant to hire a student a long period before graduation. This would imply that the job offer arrival rate is not constant in the period before graduation, but increasing as the moment of graduation approaches. Since our data are not informative on the moment of accepting a job (before graduation), we cannot identify such a non-stationary pattern in the job offer arrival rate. An alternative explanation is that the time spend on searching for work before graduation might be at the costs of study effort. In that case search effort before graduation is more expensive than while being unemployed, but this is again unidentified from the data.

Many students start searching for work relatively late and the majority of the students becomes unemployed immediately after graduation. It is therefore interesting to see to what extent the employment rate after graduation can be reduced if students would start searching for work earlier. Let's consider a policy that forces all students to start searching for work actively 6 months before 
graduation. Such a policy could for example consist of a mandatory course on job search just before the final semester, in which students are assisted in making their first job applications. If all students would actually start searching 6 months prior to graduation, employment rates at graduation would be 65 percent for economics graduates, 65 percent for business administration graduates, 62 percent for Dutch law graduates and 64 percent for psychology graduates. These percentages are remarkably close to each other. This implies that the main reason why employment rates at the moment of graduation for Dutch law and psychology graduates are lower than for economics and business administration graduates, is that they start searching for work later and not that they face more difficulties finding their first job. Furthermore, for all groups these employment rates are much higher than the current employment rates (see Table 5), so stimulating students to start searching for work earlier can be a useful policy for increasing employment rates.

\subsection{Returns to early work experience}

Our model describes individuals who first enter the labor market and who do not have any relevant work experience. In the beginning of a career wages rise faster than at any other point during the life cycle. ${ }^{15}$ Topel and Ward (1992) address that wages of young workers may increase with experience even if the true effect of work experience on labor market outcomes is zero. Labor market frictions cause that it takes some time before new entrants on the labor market reach the steady state. Wage increases in the beginning of a career may thus as well be the result of labor market frictions as of accumulated work experience.

In our model work experience is represented by the parameters $\psi_{\lambda}$ and $\psi_{\mu}$. If these parameters equal 1, labor market conditions do not change after an individual accepts his first job and all earnings increases are the consequence of labor market frictions. Recall that for all groups there are significant returns to work experience, for Dutch law and psychology graduates $\psi_{\lambda}$ differs significantly from 1 and $\psi_{\mu}$ is significantly different from 1 for economics and business administration graduates.

Substantial returns to work experience make the first job a stepping stone towards better jobs. Therefore, individuals will be less selective on their first job, i.e. reservation wages are lower while being a student or unemployed. Because they also devote more effort to job search, transition rates to work increase and employment rates just after graduation are higher. Returns to work experience

\footnotetext{
${ }^{15}$ See Figure 1 in Heckman, Lochner and Todd (2001), which shows that for all levels of education individuals have sharp increases in earnings at the beginning of their career.
} 
have a direct impact on the labor market position after accepting the first job and because individuals have been less selective on choosing their first job, the transition rate out of the first job is higher as well as the expected wage increase between the first and second job. Finally, $\bar{w}$ is higher if there are returns to work experience and thus the expected long-run wage $\mathrm{E}_{F_{e}}[W \mid W>\bar{w}]$ will be higher. We use these theoretical predictions to investigate the importance of the returns to work experience.

For each group we simulate our model twice, first using the estimated parameters and second without true returns to work experience $\psi_{\lambda}=\psi_{\mu}=1$. In the latter case all job-to-job transitions and wage increases are the consequence of labor market frictions. In Figures 9 and 10 we show the expected employment rates and the average earnings for the two years following graduation. ${ }^{16}$ The difference between both lines in the figures is the result of true returns to work experience. There are substantial differences in employment rates with and without true returns to work experience and this difference already exists at the moment of graduation. The existence of true returns to work experience causes individuals to find their first job much faster. This is mainly the result of much lower reservation wages in the presence of true returns to work experience. There is also a substantial difference in average earnings with and without true returns to work experience, i.e. average earnings are lower if $\psi_{\lambda}=\psi_{\mu}=1$. This difference in earnings in the period just after graduation should be attributed to differences in employment rates, as the average wage in the first job is much lower in case there are true returns to work experience (see Table 7). Furthermore, from Table 7 we see if there would be no returns to work experience the fraction of individuals that moves to a new job within a year after accepting the first job is reduced enormously. This reduction in job turnover is the consequence of reduced search effort while being employed due to high costs of on-the-job search. Also the wage increase associated to the move from the first to the second job is much lower if there are no returns to work experience. But this is partly the result of the lower average wages in the first job.

From the simulation experiments we conclude that true returns to work experience have a large impact on labor market outcomes. But in case there are no true returns to work experience, labor market frictions cause that earnings increase over time and individuals switch jobs and experience wage growth. The impact of labor market frictions on average labor market outcomes of a group becomes less if the duration since graduation increases, as individuals reach the steady state of the labor market. Therefore, particularly in the beginning of the

\footnotetext{
${ }^{16}$ In case an individual is unemployed his monthly earnings equal the welfare benefits of 450 euro per month.
} 
life cycle changes in average earnings increases should not all be attributed to accumulated work experience as is commonly done in Mincer earnings equations.

In the easiest specification the Mincer earnings equation predicts that over the life-cycle expected earnings depend on schooling and work experience in the following way

$$
\mathrm{E}[\log (w)]=\gamma_{0}+\gamma_{1} s+\gamma_{2} e+\gamma_{3} e^{2}
$$

where $s$ denotes years of schooling and $e$ is the years of work experience. Since our sample contains only individuals who finished undergraduate education, $s$ is the same for each individual. This implies that we can estimate $\gamma_{2}$ and $\gamma_{3}$ by

$$
\gamma_{2}=\frac{4 \mathrm{E}[\log (w) \mid e=1]-\mathrm{E}[\log (w) \mid e=2]-3 \mathrm{E}[\log (w) \mid e=0]}{2}
$$

and

$$
\gamma_{3}=\frac{\mathrm{E}[\log (w) \mid e=2]-2 \mathrm{E}[\log (w) \mid e=1]+\mathrm{E}[\log (w) \mid e=0]}{2}
$$

Using our estimated structural model we can compute for each group of graduates the expected earnings $\mathrm{E}[\log (w) \mid e=0], \mathrm{E}[\log (w) \mid e=1]$ and $\mathrm{E}[\log (w) \mid e=2]$. If we set $\psi_{\lambda}=\psi_{\mu}=1$, then there are no true returns to work experience. However as can be seen from Table 7 in this case $\gamma_{2}$ and $\gamma_{3}$ are not estimated equal to 0 . Furthermore, in Table 7 we give the estimates for $\gamma_{2}$ and $\gamma_{3}$ in case $\psi_{\lambda}$ and $\psi_{\mu}$ equal their estimated value. The sum of the two parameters equals the increase of log earnings in the first year and $\gamma_{2}+3 \gamma_{3}$ the increase in average log earnings in the second year.

\section{Conclusion}

In this paper we developed a model that describes labor market behavior of individuals around graduation. We explicitly modelled job search effort and allowed for on-the-job search. Students usually do not start working before graduating, but start searching for work prior to graduation. Therefore, our model is non stationary even if all structural parameters are stationary. In particular, some period before graduation students start searching for work with a low intensity and high reservation wages. As the moment of graduation approaches (and they have not found a job yet), students increase their job search effort and lower their reservation wage. This model is capable of explaining the common finding that a large share of students starts working immediately after graduating.

In the structural empirical analyses we have used different groups of university graduates in the Netherlands. The data describe a relatively long observation period, which allows to investigate the importance of business cycle variation on 
labor market prospects. The empirical results indicate that the business cycle is important, in particular the unemployment rate around graduation affects the wage offer distribution. If the unemployment rate decreases with 1 percent point, median wage offers increase with 3 percent.

The model provides a good fit on observed wages and transitions, but a relatively poor fit on job search effort. In particular, our model over predicts individual search effort. Contrary to our model predictions many individuals do not search on-the-job in their first job. Furthermore, individuals tend to start searching for work only a short period before graduation. Policy simulations show that employment rates at the moment of graduation could be increased from around 40 percent to 65 percent if all individuals would start job search 6 months before graduation.

Our results indicate that there are substantial returns to work experience. The existence of these returns to work experience have particularly large effects on employment rates just after graduation. Because the first job is a stepping stone towards better jobs, individuals are less selective on choosing the first job. 


\section{References}

Bloemen, H.G. (2004), Job search, search intensity and labour market transitions: an empirical analysis, Journal of Human Resources, forthcoming.

Bowlus, A.J., N.M. Kiefer, G.R. Neumann (2001), Equilibrium search models and the transition from school to work, International Economic Review 42, $317-343$.

Burdett, K. (1978), A theory of employee job search and quit rates, American Economic Review 68, 212-220.

Eckstein, Z. and K.I. Wolpin (1995), Duration to first job and the returns to schooling: estimates from a search-matching model, Review of Economic Studies 62, 263-286.

Ferrall, C. (1997), Unemployment insurance eligibility and the school-to-work transition in Canada and the United States, Journal of Business and Economic Statistics 15, 115-129.

Flinn, C.J. and J.J. Heckman (1982), New methods for analyzing structural models of labor force dynamics, Journal of Econometrics 18, 115-168.

Fougère, D., J. Pradel and M. Roger (2002), The influence of the state employment service on the search effort and on the probability of leaving unemployment, Working Paper.

Gras, A. and M. Lindeboom (1994), The search process of law graduates in the Netherlands, Working Paper, Tinbergen Institute, Amsterdam.

Heckman, J.J., L.J. Lochner and P.E. Todd (2001), Fifty years of Mincer earnings regressions, Working Paper, University of Pennsylvania, Philadelphia.

Leuven, E., H. Oosterbeek and B. van der Klaauw (2003), The effects of financial rewards on students' achievements: evidence from a randomized experiment, Working Paper, Scholar, University of Amsterdam.

Mortensen, D.T. (1977), Unemployment insurance and job search decisions, Industrial and Labor Relations Review 30, 505-517.

Mortensen, D.T. (1986), Job search and labor market analysis, in O. Ashenfelter and R. Layard (eds.), Handbook of Labor Economics, Volume 2, NorthHolland, Amsterdam.

Newey, W.K. and D. McFadden (1994), Large Sample Estimation and Hypothesis Testing, in R.F. Engle and D. McFadden (eds.), Handbook of Econometrics, Volume 4, North-Holland, Amsterdam. 
Oosterbeek, H., W. Groot and J. Hartog (1992), An empirical analysis of university choice and earnings, De Economist 140, 293-309.

Shimer, R. (2004), Search intensity, Working Paper, University of Chicago.

Stern, S. (1989), Estimating a simultaneous search model, Journal of Labor Economics 7, 348-369.

Topel, R.H. and M.P. Ward (1992), Job mobility and careers of young men, Quarterly Journal of Economics 107, 439-479.

Wolpin, K.I. (1987), Estimating a structural search model: the transition from school to work, Econometrica 55, 801-817.

Yoon, B.J. (1981), A model of unemployment duration with variable search intensity, Review of Economics and Statistics 63, 599-609. 


\section{Appendix A: Proofs of the results}

Result $1 \phi_{\tau} \geq \phi_{\tau-k}$ for all $\tau=1, \ldots$ and $k=1, \ldots, \tau$. Before graduation the reservation wage of a student $\phi_{\tau}$ is non increasing as the moment of graduation approaches.

Proof of Result 1: Rewrite equation (2) as

$$
\begin{aligned}
R_{e}\left(\phi_{\tau+1}\right)-R_{e}\left(\phi_{\tau}\right)= & \max _{s_{t} ; t=0, \ldots, \tau}\left\{-c_{u}\left(s_{\tau}\right)(1+\rho)^{\tau-1}\right. \\
& \left.+\lambda_{u}\left(s_{\tau}\right) \mathrm{E}_{F_{u}}\left[\max \left\{R_{e}(W)-R_{e}\left(\phi_{\tau}\right), 0\right\}\right]\right\}
\end{aligned}
$$

Because $c_{u}(0)=0$ and $\lambda_{u}(0)=0$, the right-hand side of the equation should be non-negative, which means $R_{e}\left(\phi_{\tau+1}\right) \geq R_{e}\left(\phi_{\tau}\right) . R_{e}(\cdot)$ is an increasing function in its argument, which implies $\phi_{\tau+1} \geq \phi_{\tau}$.

Result 2 If $s_{\tau}>0$, then $s_{\tau}<s_{\tau-k}$ for all $\tau=1, \ldots$ and $k=1, \ldots, \tau$. Students, who have not accepted a job yet, increase their job search effort as the moment of graduation gets closer.

Proof of Result 2: Recall that $\phi_{\tau} \geq \phi_{\tau-1}$. As mentioned above $\int_{\phi}^{\infty}\left[R_{e}(x)-R_{e}(\phi)\right] d F(x)$ is decreasing in $\phi$, which means

$$
\int_{\phi_{\tau}}^{\infty}\left[R_{e}(x)-R_{e}\left(\phi_{\tau}\right)\right] d F_{u}(x) \leq \int_{\phi_{\tau-1}}^{\infty}\left[R_{e}(x)-R_{e}\left(\phi_{\tau-1}\right)\right] d F_{u}(x)
$$

Since $1 /(1+\rho)^{\tau}<1 /(1+\rho)^{\tau-1}$, also

$$
\frac{c_{u}^{\prime}\left(s_{\tau}\right)}{\lambda_{u}^{\prime}\left(s_{\tau}\right)}<\frac{c_{u}^{\prime}\left(s_{\tau-1}\right)}{\lambda_{u}^{\prime}\left(s_{\tau-1}\right)}
$$

Because $c_{u}^{\prime}(s) / \lambda_{u}^{\prime}(s)$ is an increasing function in $s$, the inequality implies $s_{\tau}<s_{\tau-1}$.

Result $3 \tau_{0}$ is non decreasing if $c_{0}$ decreases, i.e. lower fixed costs of starting job search do not cause a student to start searching for work actively shorter before the moment of graduation.

Proof of Result 3: Consider the case where the fixed costs of starting job search change from $c_{0}$ to $c_{0}^{\prime}<c_{0}$. Changing the fixed costs does not affect $R_{e}\left(\phi_{\tau}\right)$. Therefore, we can rewrite

$$
R_{e}\left(\phi_{\tau}\right)-c_{0}^{\prime}(1+\rho)^{\tau-1}=R_{e}\left(\phi_{\tau}\right)-c_{0}(1+\rho)^{\tau-1}-\left(c_{0}^{\prime}-c_{0}\right)(1+\rho)^{\tau-1}
$$


Since for any moment $\tau<\tau_{0}$

$$
R_{e}\left(\phi_{\tau_{0}}\right)-c_{0}(1+\rho)^{\tau_{0}-1}>R_{e}\left(\phi_{\tau}\right)-c_{0}(1+\rho)^{\tau-1}
$$

we can show that

$$
\begin{aligned}
R_{e}\left(\phi_{\tau_{0}}\right)-c_{0}^{\prime}(1+\rho)^{\tau_{0}-1} & =R_{e}\left(\phi_{\tau_{0}}\right)-c_{0}(1+\rho)^{\tau_{0}-1}-\left(c_{0}^{\prime}-c_{0}\right)(1+\rho)^{\tau_{0}-1} \\
& >R_{e}\left(\phi_{\tau}\right)-c_{0}(1+\rho)^{\tau-1}-\left(c_{0}^{\prime}-c_{0}\right)(1+\rho)^{\tau_{0}-1} \\
& >R_{e}\left(\phi_{\tau}\right)-c_{0}(1+\rho)^{\tau-1}-\left(c_{0}^{\prime}-c_{0}\right)(1+\rho)^{\tau-1} \\
& =R_{e}\left(\phi_{\tau}\right)-c_{0}^{\prime}(1+\rho)^{\tau-1}
\end{aligned}
$$

And thus

$$
\arg \max _{\tau=1, \ldots}\left\{R_{e}\left(\phi_{\tau}\right)-c_{0}^{\prime}(1+\rho)^{\tau-1}\right\} \geq \tau_{0}
$$

Result 4 The moment $\tau_{0}$ at which a student starts searching for work is unique or non-existing.

Proof of Result 4: Note that

$$
\begin{aligned}
R_{e}\left(\phi_{\tau+1}\right)-R_{e}\left(\phi_{\tau}\right)= & \max _{s_{t} ; t=1, \ldots, \tau}\left\{-c_{u}\left(s_{\tau}\right)(1+\rho)^{\tau-1}\right. \\
& \left.+\lambda_{u}\left(s_{\tau}\right) \mathrm{E}_{F_{u}}\left[\max \left\{R_{e}(W)-R_{e}\left(\phi_{\tau}\right), 0\right\}\right]\right\} \\
= & (1+\rho)^{\tau-1}\left\{\lambda_{u}\left(s_{\tau}\right) \frac{c_{u}^{\prime}\left(s_{\tau}\right)}{\lambda_{u}^{\prime}\left(s_{\tau}\right)}-c_{u}\left(s_{\tau}\right)\right\}
\end{aligned}
$$

where in the last line $s_{\tau}$ is the optimal amount of job search effort in period $\tau$. The right-hand side is strictly positive. The first term $(1+\rho)^{\tau-1}$ is increasing in $\tau$, but the second term is decreasing in $\tau$, as we know that the term increases in $s_{\tau}$ and $s_{\tau+1}<s_{\tau}$. Next note that

$$
c_{0}(1+\rho)^{\tau}-c_{0}(1+\rho)^{\tau-1}=\rho c_{0}(1+\rho)^{\tau-1}
$$

which also increases in $\tau$. Comparing these equations proves that as long as

$$
\lambda_{u}\left(s_{\tau}\right) \frac{c_{u}^{\prime}\left(s_{\tau}\right)}{\lambda_{u}^{\prime}\left(s_{\tau}\right)}-c\left(s_{\tau}\right)>\rho c_{0}
$$

$R_{e}\left(\phi_{\tau}\right)-c_{0}(1+\rho)^{\tau-1}$ increases in $\tau$, otherwise it is decreasing. Since the left-hand side decreases in $\tau$ and the right-hand side does not depend on $\tau$, there exists a unique $\tau_{0}$.

However, if at the optimal moment of starting job search the returns to job search are lower than the present value of the fixed search costs, $R_{e}\left(\phi_{\tau_{0}}\right)<c_{0}(1+\rho)^{\tau_{0}-1}$, the student will not start searching at all before graduation. In this case $\tau_{0}$ is non-existing. 
Result $5 \theta_{\tau}<\theta_{\tau-k}$ for all $\tau=1, \ldots, \tau_{0}$ and $k=1, \ldots, \tau$.

Proof of Result 5: Recall that $s_{\tau}$ is decreasing in $\tau$ and $\phi_{\tau}$ is non decreasing in $\tau$. Since $\lambda_{u}\left(s_{\tau}\right)$ is an increasing function in $s_{\tau}$, it is decreasing in $\tau$. Furthermore, $\left(1-F_{u}\left(\phi_{\tau}\right)\right)$ is decreasing in $\phi_{\tau}$ and thus it is decreasing $\tau$. As a result $\theta_{\tau}$ is decreasing in $\tau$.

Result 6 There exists a wage level $\bar{w}$, for which $s=0$ if $w \geq \bar{w}$. For $w<\bar{w}, s$ is positive and decreasing in w. A worker reduces his job search effort if he receives a higher wage. If the wage exceeds a certain level, the worker does not devote any effort to job search.

Proof of Result 6: Consider the condition for devoting a positive amount of effort to job search

$$
\frac{c_{e}^{\prime}(0)}{\lambda_{e}^{\prime}(0)}<\int_{w}^{\infty}\left[R_{e}(x)-R_{e}(w)\right] d F_{e}(x)
$$

The left-hand side of the equation is positive. The right-hand side is also positive. To show that there exists some $\bar{w}$ above which individuals stop devoting effort to job search, we have to show that the right-hand side is decreasing in $w$ and becomes 0 if $w$ approaches infinity. The derivative of the right-hand side with respect to $w$ equals

$$
-\frac{\partial R_{e}(w)}{\partial w}\left(1-F_{e}(w)\right)
$$

which is negative, because $R_{e}(w)$ is an increasing function in $w$. Next we show that if $w$ approaches infinity the right-hand side of the condition for positive job search effort becomes 0 . Note that $R_{e}(x)-R_{e}(w) \leq x-w$ for $x \geq w$. This means

$$
\int_{w}^{\infty}\left[R_{e}(x)-R_{e}(w)\right] d F_{e}(x) \leq \int_{w}^{\infty}(x-w) d F_{e}(x)=\mathrm{E}_{F_{e}}[W]-\int_{0}^{w}\left(1-F_{e}(x)\right) d x
$$

The wage offer distribution $F_{e}(\cdot)$ has a finite mean and

$$
\lim _{w \rightarrow \infty} \int_{0}^{w}\left(1-F_{e}(x)\right) d x=\mathrm{E}_{F_{e}}[W]
$$

Therefore

$$
\lim _{w \rightarrow \infty} \int_{w}^{\infty}\left[R_{e}(x)-R_{e}(w)\right] d F_{e}(x)=0
$$

Next, we already have seen that $\frac{c_{e}^{\prime}(s)}{\lambda_{e}^{\prime}(s)}$ is an increasing function in $s$. Since $\int_{w}^{\infty} R_{e}(x)-$ $R_{e}(w) d F_{e}(x)$ decreases in $w$, search effort decreases in $w$ for $w<\bar{w}$. 


\begin{tabular}{lr}
\hline \hline & Total \\
\hline \hline Economics & 1288 \\
Business (Administration) & 741 \\
Dutch Law & 875 \\
Psychology & 630 \\
\hline \hline Total & 3534 \\
\hline \hline
\end{tabular}

Table 1: Sample size stratified by study.

\begin{tabular}{lccccccc}
\hline \hline & \multicolumn{7}{c}{ Year of interview } \\
& $\mathbf{1 9 9 7}$ & $\mathbf{1 9 9 8}$ & $\mathbf{1 9 9 9}$ & $\mathbf{2 0 0 0}$ & $\mathbf{2 0 0 1}$ & $\mathbf{2 0 0 2}$ & $\mathbf{2 0 0 3}$ \\
\hline \hline Economics & 1301 & 1321 & 1337 & 1435 & 1426 & 1544 & 1392 \\
Business & 1345 & 1317 & 1387 & 1440 & 1422 & 1500 & 1449 \\
Dutch Law & 1274 & 1243 & 1279 & 1359 & 1402 & 1500 & 1356 \\
Psychology & 1102 & 1081 & 1200 & 1196 & 1173 & 1219 & 1220 \\
\hline \hline
\end{tabular}

Table 2: The average real monthly net wage of employed individuals at the moment of the questionnaire (in euros in February 1997).

\begin{tabular}{lrrrrrrr}
\hline \hline & \multicolumn{7}{c}{ Year of interview } \\
& $\mathbf{1 9 9 7}$ & $\mathbf{1 9 9 8}$ & $\mathbf{1 9 9 9}$ & $\mathbf{2 0 0 0}$ & $\mathbf{2 0 0 1}$ & $\mathbf{2 0 0 2}$ & $\mathbf{2 0 0 3}$ \\
\hline \hline Economics & 13.4 & 12.1 & 11.6 & 7.8 & 5.2 & 4.7 & 5.6 \\
Business & 9.5 & 11.8 & 11.1 & 8.4 & 6.0 & 7.5 & 9.0 \\
Dutch law & 16.8 & 16.6 & 15.6 & 9.8 & 7.3 & 5.1 & 7.0 \\
Psychology & 13.3 & 17.5 & 14.3 & 9.9 & 15.1 & 13.1 & 11.0 \\
\hline \hline
\end{tabular}

Explanatory note: In the 1997 and 1998 surveys individuals were asked to report the number of job applications until accepting the first job. Since 1999 individuals have to report the total number of job applications until the moment of the survey.

Table 3: Number of job applications. 


\begin{tabular}{lcccc}
\hline \hline & Economics & Business & Dutch law & Psychology \\
\hline \hline Job offer arrival rate $\lambda$ & & & & \\
\hline Intercept & -0.774 & -1.283 & -1.749 & -1.150 \\
& $(0.347)$ & $(0.191)$ & $(0.178)$ & $(0.245)$ \\
Individual characteristics & & & & \\
Average level of grades in study & & & & \\
Medium grades & -0.312 & 0.068 & -0.118 & -0.185 \\
High grades & $(0.062)$ & $(0.079)$ & $(0.081)$ & $(0.113)$ \\
& -0.172 & 0.030 & -0.099 & -0.148 \\
Male & $(0.086)$ & $(0.101)$ & $(0.100)$ & $(0.139)$ \\
Higher education farther & & & & \\
& -0.210 & -0.317 & -0.113 & -0.141 \\
Older than 25 years & $(0.066)$ & $(0.070)$ & $(0.078)$ & $(0.109)$ \\
& -0.121 & -0.109 & -0.126 & -0.096 \\
West & $(0.056)$ & $(0.072)$ & $(0.073)$ & $(0.101)$ \\
& -0.102 & -0.021 & -0.229 & -0.030 \\
& $(0.065)$ & $(0.070)$ & $(0.079)$ & $(0.110)$ \\
$\chi^{2}$-tests for joint significance & 0.122 & -0.133 & 0.070 & 0.114 \\
Business cycle variation & $(0.058)$ & $(0.074)$ & $(0.075)$ & $(0.104)$ \\
GDP growth & 44.6 & 38.5 & 15.3 & 6.9 \\
Unemployment rate & & & & \\
& & & & \\
$\chi^{2}$-tests for joint significance & 3.2 & 5.0 & 6.5 & 18.7 \\
\hline \hline
\end{tabular}

Table 4: Results of the structural model. 


\begin{tabular}{|c|c|c|c|c|}
\hline & Economics & Business & Dutch law & $\overline{\text { Psychology }}$ \\
\hline \multicolumn{5}{|l|}{ "Mean log earnings level $\mu$} \\
\hline Intercept & $\begin{array}{c}7.115 \\
(0.059)\end{array}$ & $\begin{array}{c}7.130 \\
(0.042)\end{array}$ & $\begin{array}{c}7.199 \\
(0.034)\end{array}$ & $\begin{array}{c}7.272 \\
(0.047)\end{array}$ \\
\hline \multicolumn{5}{|l|}{ Individual characteristics } \\
\hline \multicolumn{5}{|l|}{ Average level of grades in study } \\
\hline Medium grades & $\begin{array}{c}0.064 \\
(0.013)\end{array}$ & $\begin{array}{c}0.048 \\
(0.017)\end{array}$ & $\begin{array}{c}0.033 \\
(0.017)\end{array}$ & $\begin{array}{c}0.026 \\
(0.024)\end{array}$ \\
\hline High grades & $\begin{array}{c}0.092 \\
(0.016)\end{array}$ & $\begin{array}{c}0.062 \\
(0.023)\end{array}$ & $\begin{array}{c}0.029 \\
(0.023)\end{array}$ & $\begin{array}{c}0.052 \\
(0.032)\end{array}$ \\
\hline Male & $\begin{array}{c}0.045 \\
(0.013)\end{array}$ & $\begin{array}{c}0.073 \\
(0.015)\end{array}$ & $\begin{array}{c}0.001 \\
(0.015)\end{array}$ & $\begin{array}{c}0.018 \\
(0.020)\end{array}$ \\
\hline Higher education farther & $\begin{array}{c}0.043 \\
(0.012)\end{array}$ & $\begin{array}{c}0.001 \\
(0.015)\end{array}$ & $\begin{array}{c}0.057 \\
(0.015)\end{array}$ & $\begin{array}{c}0.050 \\
(0.020)\end{array}$ \\
\hline Older than 25 years & $\begin{array}{c}0.031 \\
(0.013)\end{array}$ & $\begin{array}{c}0.006 \\
(0.016)\end{array}$ & $\begin{array}{c}0.045 \\
(0.015)\end{array}$ & $\begin{array}{r}-0.026 \\
(0.021)\end{array}$ \\
\hline West & $\begin{array}{c}0.017 \\
(0.012)\end{array}$ & $\begin{array}{c}0.068 \\
(0.015)\end{array}$ & $\begin{array}{c}0.053 \\
(0.016)\end{array}$ & $\begin{array}{r}-0.058 \\
(0.022)\end{array}$ \\
\hline$\chi^{2}$-tests for joint significance & 73.3 & 55.4 & 48.1 & 16.1 \\
\hline \multicolumn{5}{|l|}{ Business cycle variation } \\
\hline GDP growth & $\begin{array}{c}0.001 \\
(0.003)\end{array}$ & $\begin{array}{r}-0.003 \\
(0.004)\end{array}$ & $\begin{array}{r}-0.005 \\
(0.004)\end{array}$ & $\begin{array}{r}-0.006 \\
(0.005)\end{array}$ \\
\hline Unemployment rate & $\begin{array}{c}-0.032 \\
(0.004)\end{array}$ & $\begin{array}{c}-0.026 \\
(0.004)\end{array}$ & $\begin{array}{c}-0.033 \\
(0.005)\end{array}$ & $\begin{array}{c}-0.028 \\
(0.006)\end{array}$ \\
\hline$\chi^{2}$-tests for joint significance & 96.1 & 41.0 & 54.2 & 20.6 \\
\hline
\end{tabular}

Table 4: (Continued). 


\begin{tabular}{|c|c|c|c|c|}
\hline & Economics & Business & Dutch law & Psychology \\
\hline \multicolumn{5}{|c|}{ Additional parameters } \\
\hline \multirow[t]{2}{*}{$c$} & 3.362 & 4.044 & 2.630 & 2.957 \\
\hline & $(0.112)$ & $(0.191)$ & $(0.104)$ & $(0.140)$ \\
\hline \multirow[t]{2}{*}{$\psi_{\lambda}$} & 2.515 & 2.530 & 9.297 & 6.182 \\
\hline & (1.993) & (1.424) & $(3.272)$ & $(0.934)$ \\
\hline \multirow[t]{2}{*}{$\psi_{\mu}$} & 1.009 & 1.009 & 0.998 & 0.995 \\
\hline & $(0.004)$ & $(0.003)$ & $(0.002)$ & $(0.003)$ \\
\hline \multirow[t]{2}{*}{$\psi_{c}$} & 11.282 & 6.847 & 12.082 & 5.506 \\
\hline & $(1.880)$ & (1.114) & $(3.074)$ & $(0.873)$ \\
\hline \multirow[t]{2}{*}{$\sigma$} & 0.168 & 0.180 & 0.158 & 0.151 \\
\hline & $(0.022)$ & $(0.015)$ & $(0.013)$ & $(0.017)$ \\
\hline \multirow[t]{2}{*}{$\sigma_{\varepsilon}$} & 0.180 & 0.144 & 0.162 & 0.248 \\
\hline & $(0.004)$ & $(0.007)$ & $(0.006)$ & $(0.013)$ \\
\hline \multirow[t]{2}{*}{$\sigma_{s}$} & 0.950 & 0.978 & 1.046 & 0.932 \\
\hline & $(0.017)$ & $(0.023)$ & $(0.021)$ & $(0.022)$ \\
\hline
\end{tabular}

Table 4: (Continued).

\begin{tabular}{l|rr|rr|rr|rr}
\hline \hline & \multicolumn{2}{|c|}{ Economics } & \multicolumn{2}{|c|}{ Business } & \multicolumn{2}{c|}{ Dutch law } & \multicolumn{2}{c}{ Psychology } \\
\hline & \multicolumn{1}{|c|}{ pred. } & obs. & pred. & obs. & pred. & obs. & pred. & obs. \\
\hline Number of jobs at survey date & & & & & & & & \\
No jobs & 1.0 & 0.3 & 1.1 & 0.1 & 2.3 & 0.7 & 3.8 & 2.4 \\
1 job & 60.3 & 62.5 & 52.7 & 55.3 & 49.1 & 53.5 & 43.5 & 39.2 \\
2 jobs & 32.2 & 28.4 & 37.0 & 34.7 & 36.1 & 30.7 & 35.7 & 36.5 \\
3 or more jobs & 6.5 & 8.7 & 9.2 & 9.9 & 12.5 & 15.1 & 17.0 & 21.9 \\
& & & & & & & & \\
Employed rate at graduation & 44.2 & 44.3 & 41.2 & 42.6 & 33.9 & 32.5 & 33.8 & 34.6 \\
\hline \hline
\end{tabular}

Table 5: Observed and predicted distribution of number of jobs at moment of survey and employment rate at graduation. 


\begin{tabular}{lcc}
\hline \hline & \multicolumn{2}{c}{ True returns to work experience } \\
& Yes & No \\
\hline \hline \multicolumn{2}{c}{ Average wage } & in first job \\
\hline Economics & 1342.1 & 1544.4 \\
Business & 1318.3 & 1523.5 \\
Dutch law & 1268.9 & 1548.5 \\
Psychology & 1278.2 & 1443.3 \\
\hline Fraction changing jobs within year after accepting first job \\
\hline Economics & 0.34 & 0.02 \\
Business & 0.40 & 0.05 \\
Dutch law & 0.47 & 0.01 \\
Psychology & 0.53 & 0.07 \\
\hline Average wage & increase between first and second job \\
\hline Economics & 172.7 & 117.5 \\
Business & 225.9 & 147.5 \\
Dutch law & 165.8 & 116.1 \\
Psychology & 155.4 & 127.6 \\
\hline \hline
\end{tabular}

Table 6: Results from simulation experiments on the importance on true returns to work experience.

\begin{tabular}{|c|c|c|c|c|}
\hline & Economics & Business & Dutch Law & Psychology \\
\hline \multicolumn{5}{|c|}{ Mincer earnings regression with $\psi_{\lambda}=\psi_{\mu}=1$} \\
\hline$\gamma_{2}$ & 0.4206 & 0.4439 & 0.3549 & 0.5227 \\
\hline$\gamma_{3}$ & -0.0555 & -0.0649 & -0.0388 & -0.0897 \\
\hline \multicolumn{5}{|c|}{ With true returns to work experience } \\
\hline$\gamma_{2}$ & 0.7505 & 0.5761 & 0.7109 & 0.6508 \\
\hline$\gamma_{3}$ & -0.1939 & -0.1150 & -0.1649 & -0.1384 \\
\hline
\end{tabular}

Table 7: Results of the simulations with the Mincer equation. 


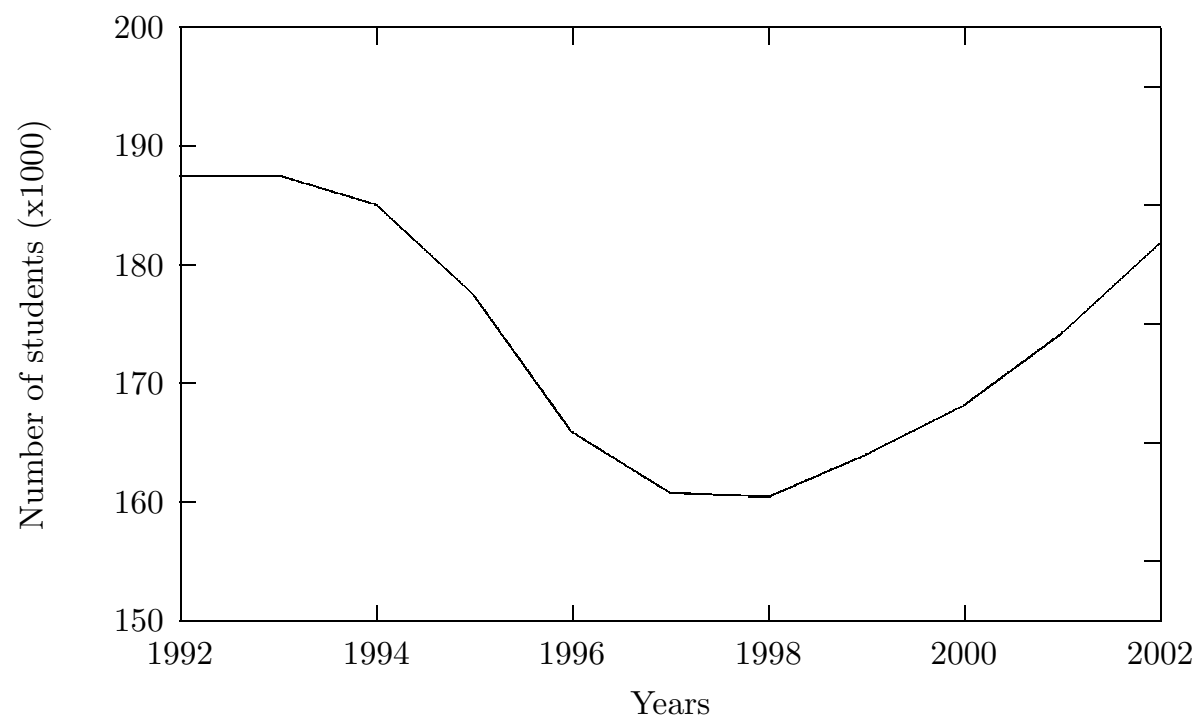

Figure 1: The total number of students $(\times 1000)$ registered at Dutch universities (source: Statistics Netherlands).

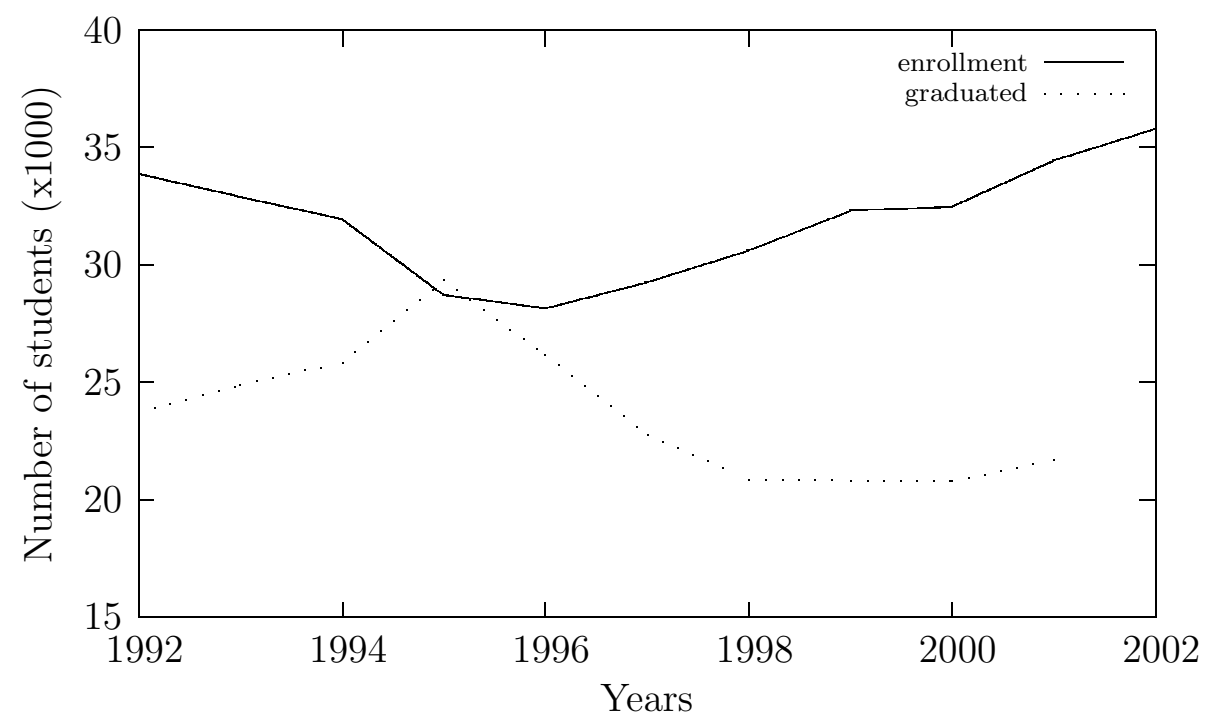

Figure 2: The number of students $(\times 1000)$ enrolling in the first year and graduating (source: Statistics Netherlands). 


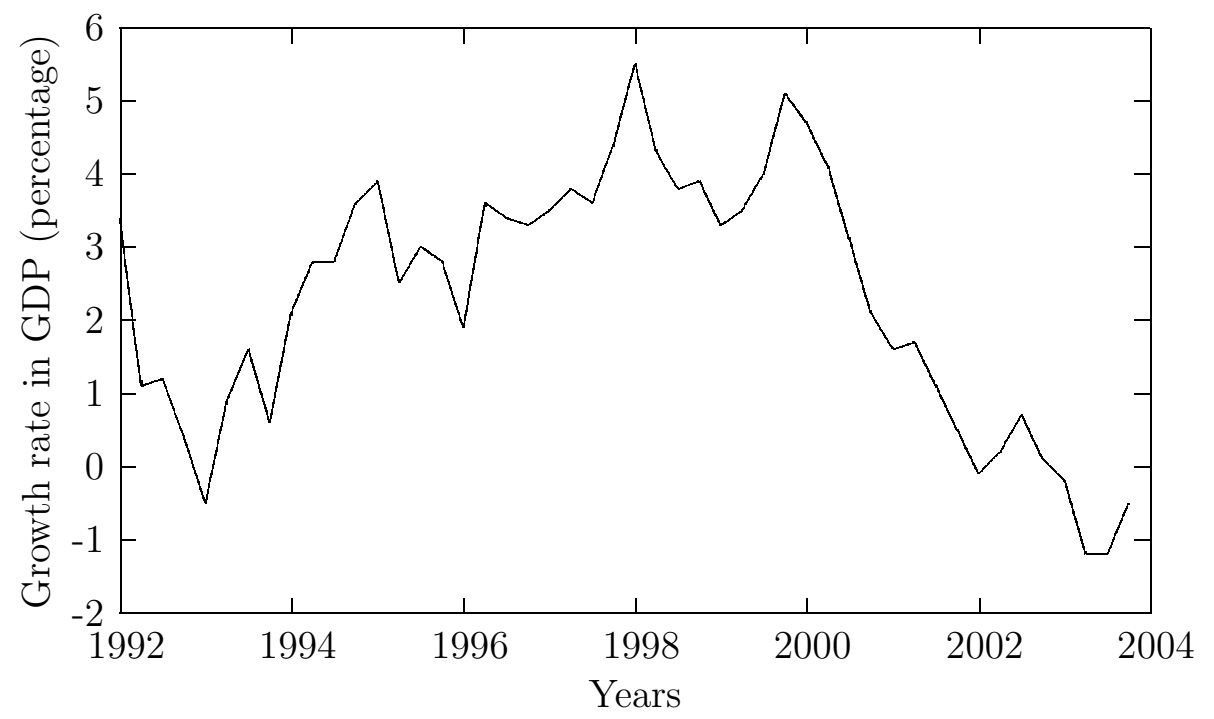

Figure 3: Economic growth measured in percentage increases in GDP (source: Statistics Netherlands).

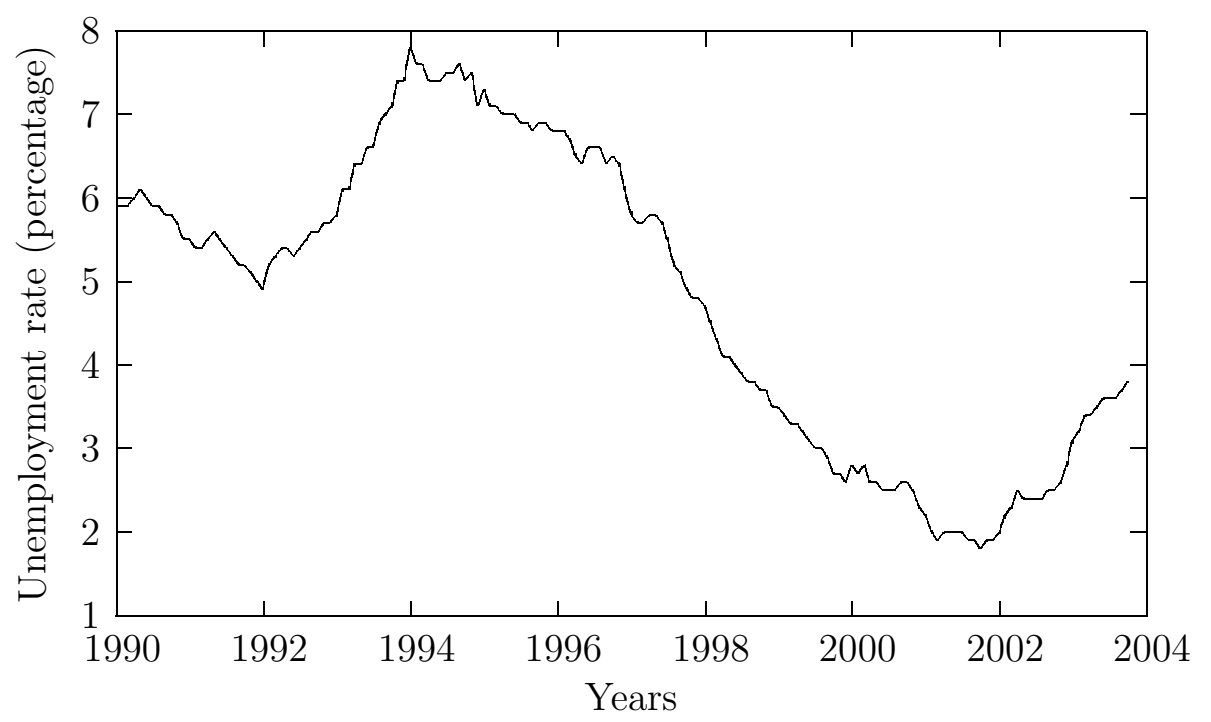

Figure 4: The unemployment rate (in percentage) (source: Statistics Netherlands). 


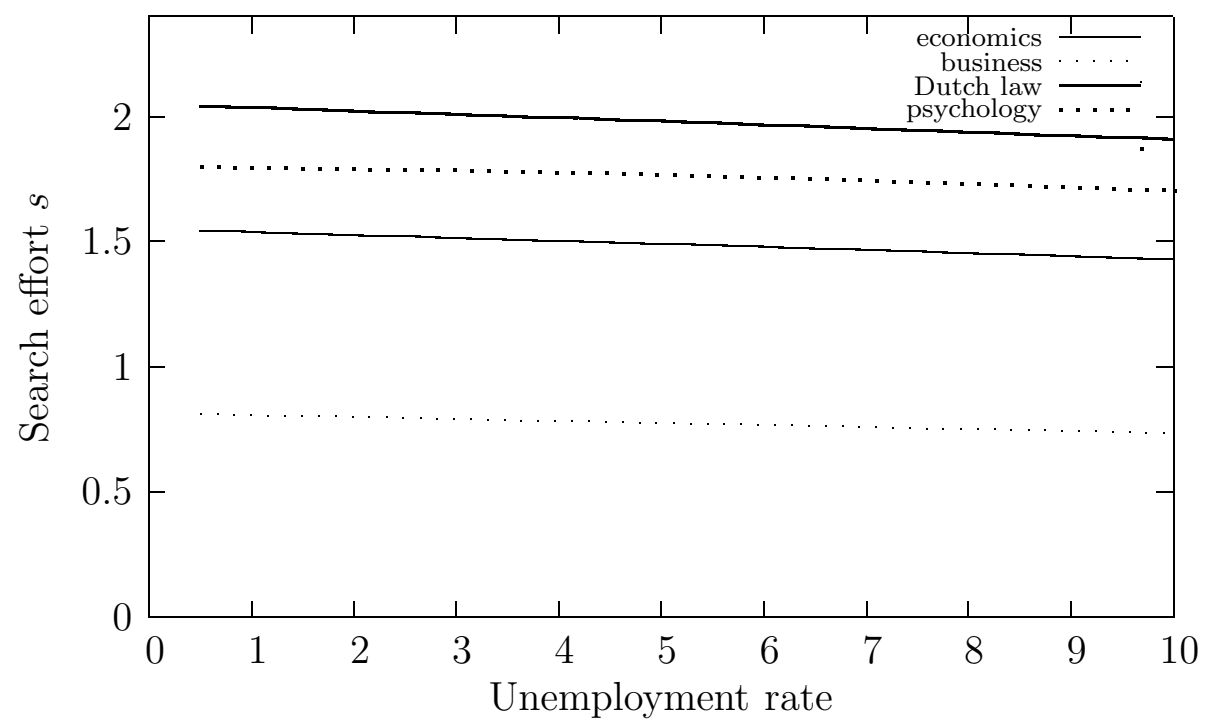

Figure 5: Optimal monthly job search effort (measured in job applications) at the moment of graduation as function of the unemployment rate.

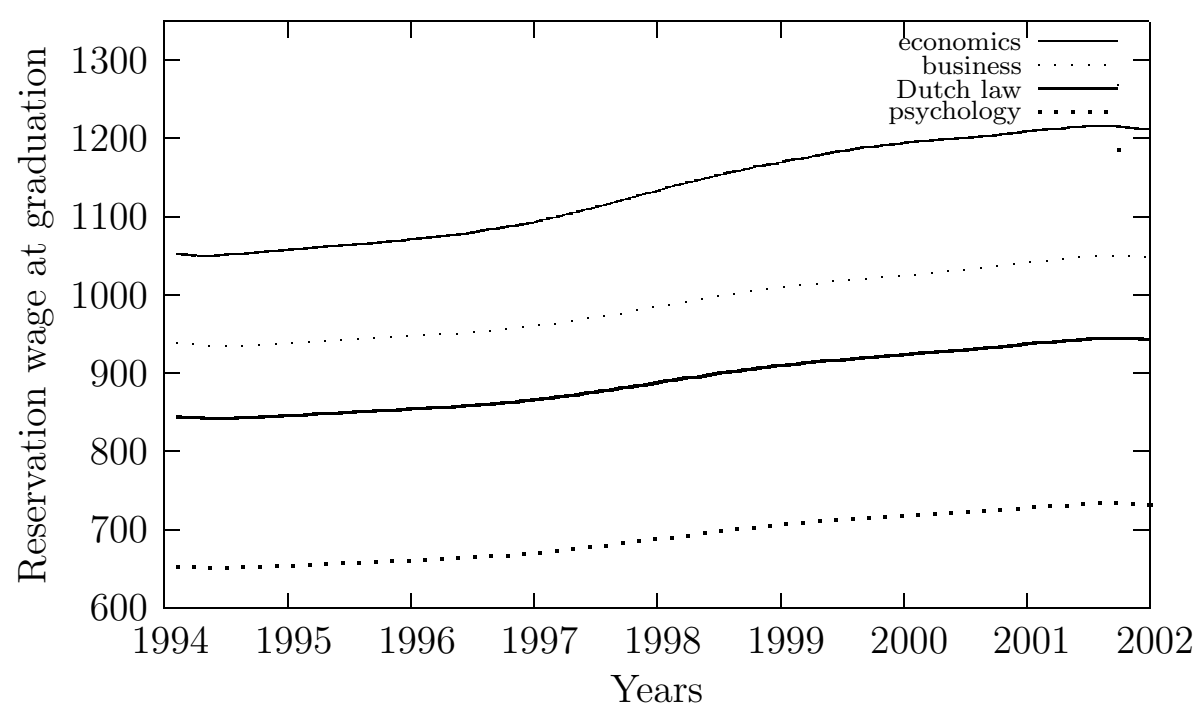

Figure 6: Changes in the reservation wage $(\phi)$ at the moment of graduation over calendar time. 


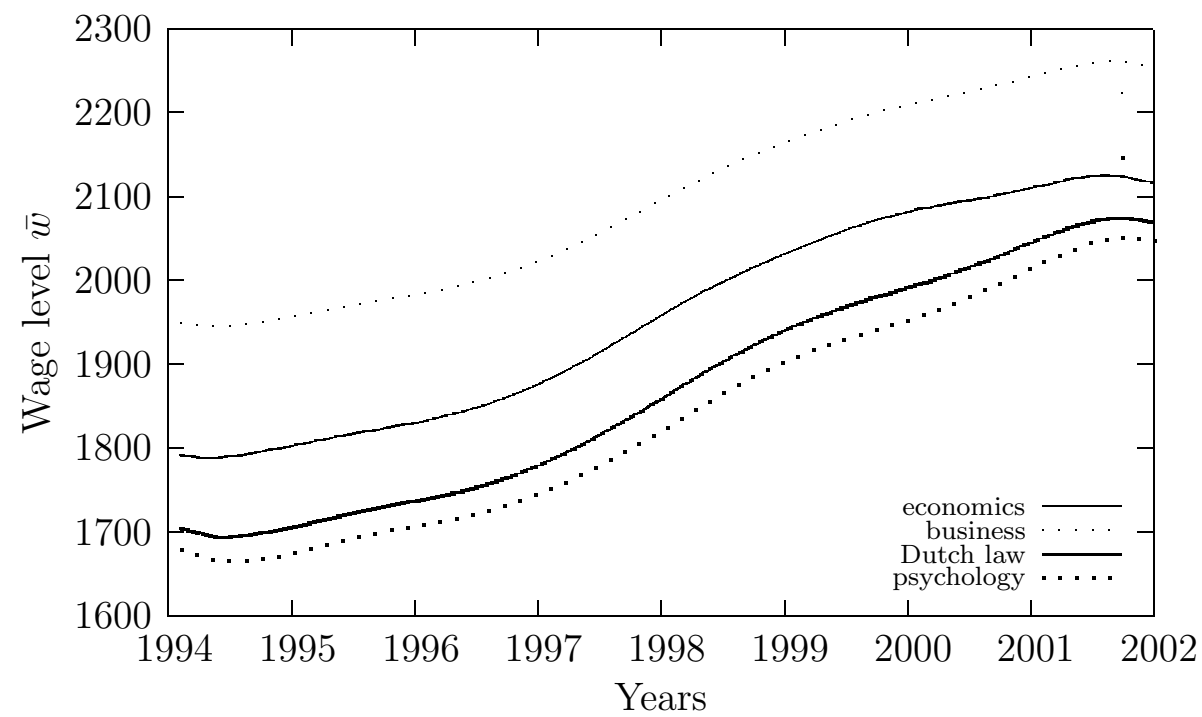

Figure 7: Changes in lowest wage at which individuals do not search on-the-job $(\bar{w})$ over calendar time.
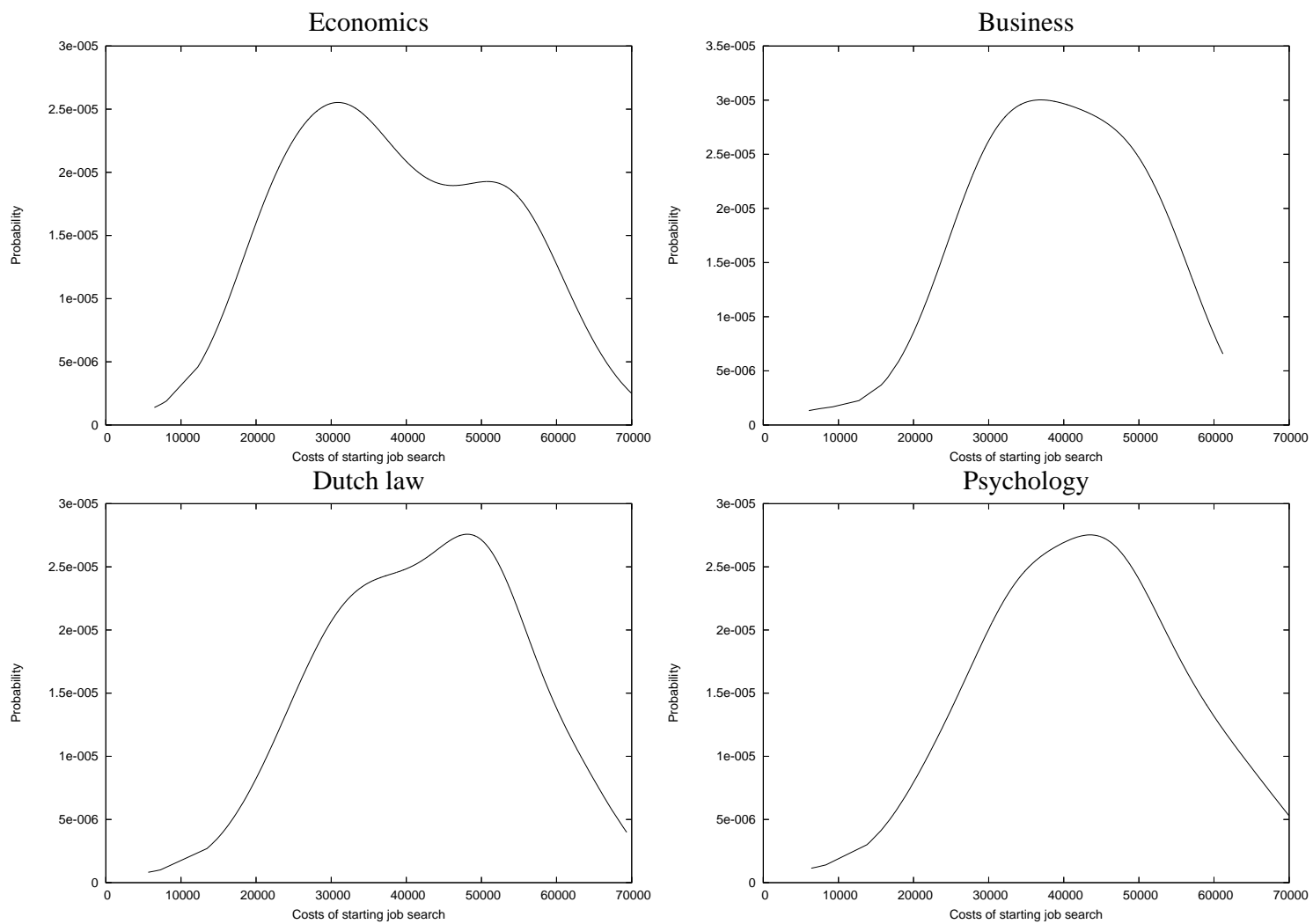

Figure 8: Non-parametric density estimations of the search start-up costs. 

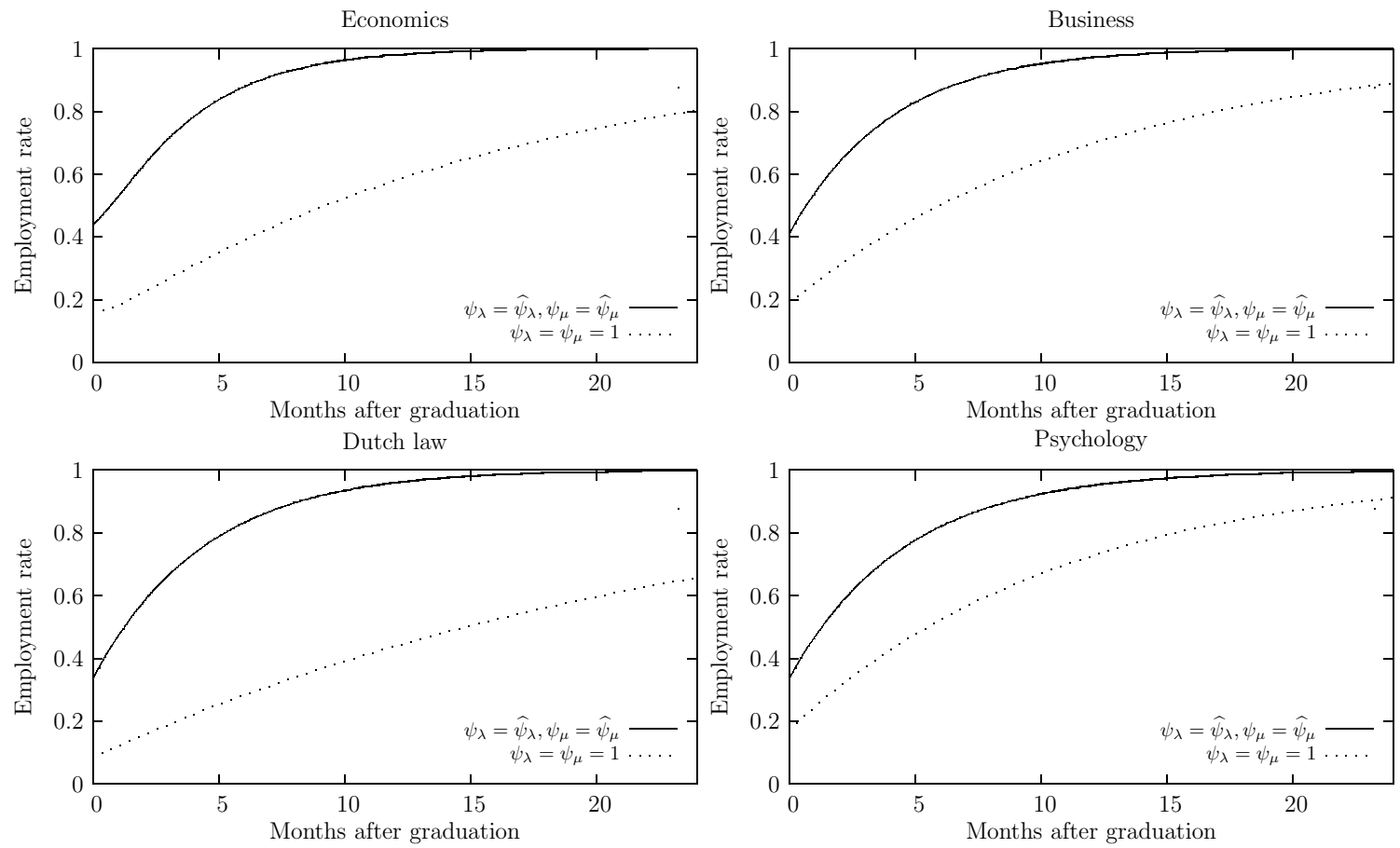

Figure 9: Simulated employment rates two years following graduation.
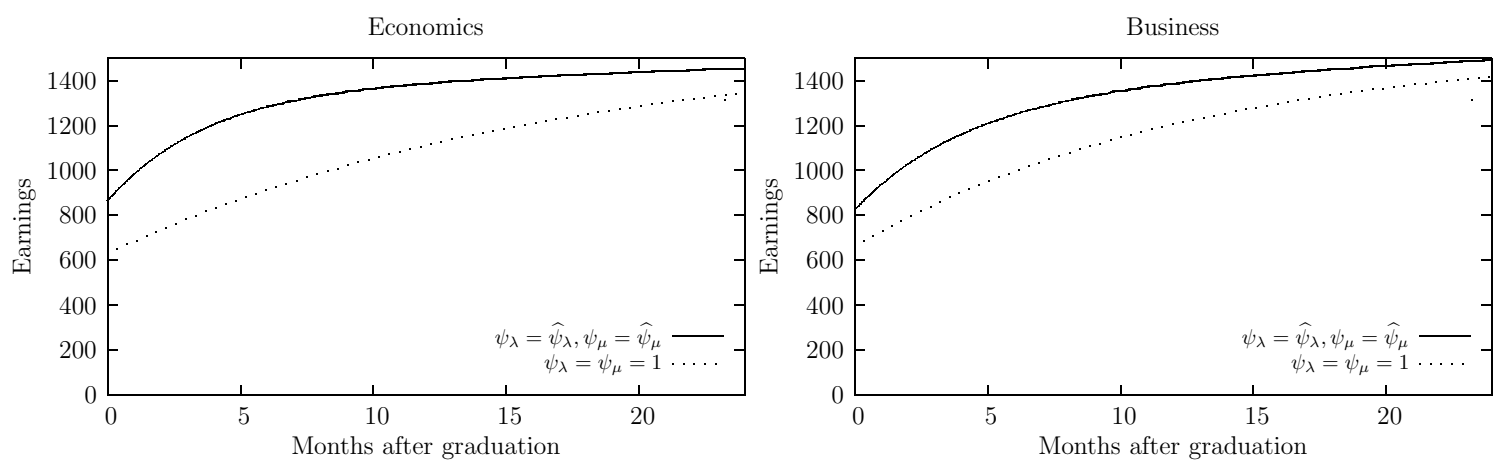
Dutch law
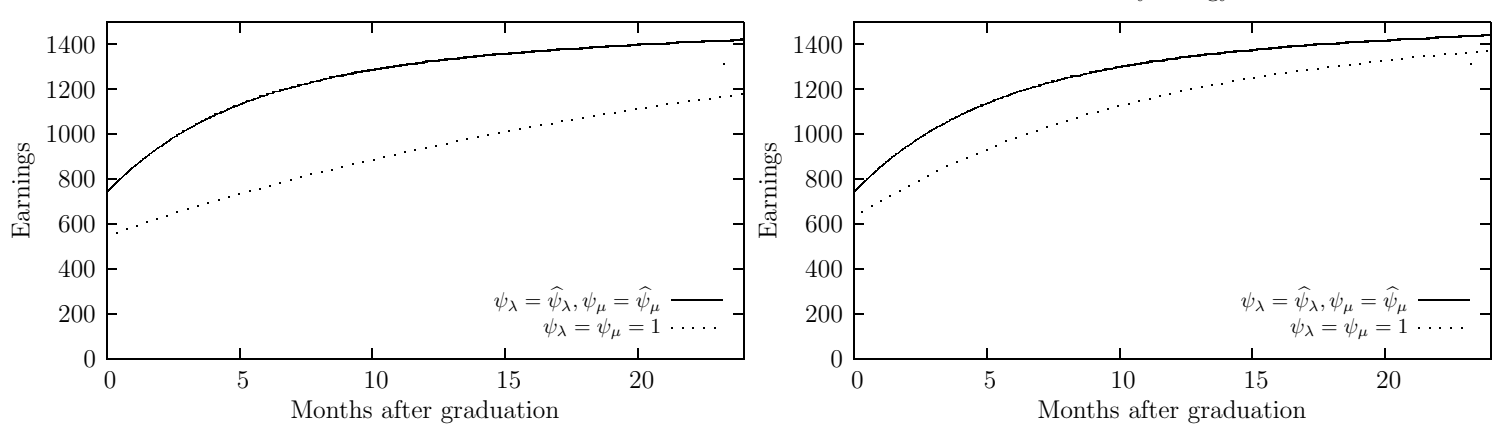

Figure 10: Simulated average earnings two years following graduation 